\title{
Creativity and fixation in the real world: three case studies of invention, design and innovation
}

Nathan Crilly \& Roxana Moroşanu Firth, University of Cambridge

Abstract: This paper reports on the design of three novel products: a hand saw, electrical plug and bicycle wheel. Each case study draws on interviews with the designers and analysis of their prototypes. The focus is on how the product ideas originated, how and why they changed and why those changes weren't made earlier. In emphasising the nature of creative work throughout long and complex projects, three themes are emphasised: (1) creative challenges and creative blocks can result from earlier breakthroughs (which makes them difficult to overcome); (2) multiple design spaces co-evolve at different levels of detail (not just simple problem- and solution-spaces); (3) those developing new ideas need to recognise and accept those ideas (not just generate and develop them).

Keywords: creative design, creativity, design fixation, product development, prototypes

"Interesting creative processes almost never result from single steps, but rather from concatenations and articulation of a complex set of interrelated moves"

(Gruber 1980: p. 177) 
A review of design creativity case studies indicated the need for detailed descriptions of how design ideas develop 'in the real world', including episodes where fixation occurs, is overcome or is avoided (Crilly, in press). In response, we here report on three case studies of invention, design and innovation. The projects resulted in commercially available products, with each being radically (rather than incrementally) different to preceding products within the same category. The case studies are based on interviews with the designers who developed the products, focussing on their accounts of where the design ideas came from, how they changed over time and what factors shaped that development. These accounts are supported with illustrations of the sketches, models and prototypes that document the evolution of the product ideas over the months and years that the projects were being undertaken. Individually, the cases provide descriptions of how design ideas are influenced by factors such as problem discovery, initial assumptions, prior products, competing objectives, regulations, production costs and market forces. Collectively, the cases illustrate different ways in which design work is performed over long periods and they emphasise the role of creativity not just in early-stage ideation, but throughout the design process. In reporting these projects, we first emphasise the particular rather than the general, aiming to describe how the ideas progressed, and then identify general themes that might apply beyond the particular cases. This provides individual project descriptions and more abstract concepts that can be referred to or used in future work, irrespective of the research methods that such work employs (e.g. experiments, surveys, observations or interviews). We suggest that a collection of detailed case studies like these are required if design researchers are to develop a more complete representation of creative design work, and an understanding of how contemporary experimental research relates to design as it occurs in the wild. In the remainder of this paper we aim to contribute to a collection of that kind.

\section{Method}

Three case studies were conducted, each focussing on projects that involved the development of a radically new product rather than some incremental advance. To permit each of the cases to be better understood, we here describe how the projects were identified, how the data was collected and how the reports were produced.

To permit the study of creative work in the design process, we sought project examples where a change in the product was clearly evident, either from prototype to production, from one product generation to another, or from one product line to the next. In identifying projects for inclusion in the study, four criteria were applied. 
- Each project was to be focussed on the development of a physical product rather than, for example, electronics, software, services or processes. This would have the methodological advantage of making the details of the accounts more accessible to the researchers (based on their knowledge and experience). It would also have the theoretical advantage of connecting the cases to the majority of studies on design creativity (where it is physical product ideas that are typically developed).

- The products were to be commercially available. This would have the methodological advantage that discussions would not be inhibited by participants withholding information that would only become public knowledge at the point of market launch (if at all). It would also have the theoretical advantage that any design issues surrounding manufacture, distribution and sales would have already been addressed (rather than just early-stage ideation, as is typically studied in design creativity research).

- There was to be a single person clearly identifiable as the designer of each product. This would have the methodological advantage of permitting a single participant to know about and have records of most aspects project development. It would also have the theoretical advantage of connecting the cases to the majority of studies on design creativity (where individual work is typically studied).

- Finally, there was to be substantial information about the project already in the public record. This had three methodological advantages: (1) identification of potential cases would be easier (for example, considering the criteria above); (2) it would indicate that confidentiality requirements would not prevent participants disclosing (and the researchers reporting) the most relevant details of the projects; (3) it would make it easier for the researchers to prepare for the interviews.

In accordance with the last criterion, the researchers surveyed marketing material, press releases and media stories to identify possible cases, excluding those that didn't satisfy the first three criteria. Three projects were identified, with the corresponding individuals approached for interview: all accepted. For consistency with the literature, these individuals are referred to here as 'designers' and it is that role that we focus on, even though they all performed multiple roles, including production, marketing, management and finance (as is common for entrepreneurs and small organisations). We restricted the study to only three cases so that each could be reported in sufficient detail to draw out their complexity and to permit the cases to be adequately illustrated with the visual materials that are required to understand the projects and their evolution. 
During May, June and July 2017, the designers were recruited into the study with a request to discuss the development of design ideas with respect to the specific products that had been identified. The interviews were conducted either face-to-face or over two-way video links. All interviews involved the designers sharing representations (including sketches and prototypes) of how their ideas developed. The interviews focussed on exploring the changes from one iteration to the next, including the processes by which those changes occurred and the reasons such changes weren't made earlier. With the participants' consent, all interviews were audio recorded, with video and screen recording used to capture any visual information necessary for understanding the details conveyed verbally. Each participant was interviewed individually and these interviews were augmented with email exchanges to share further information about the projects of interest. In addition, the participants provided further visual materials in the form of drawings and photographs to help in reconstructing the story for each product.

All audio recordings were transcribed verbatim (totalling 23,000 words) with cross references to visual records of the sketches and prototypes that were being discussed. The transcripts and other materials were reviewed independently by two researchers, one with a background in design and engineering and one with a background in anthropology and technology. Both had prior experience of conducting interview studies and analysing the resulting data. The review of the transcripts involved two distinct phases: narrative analysis and thematic analysis. During narrative analysis (see section 3), the researchers focussed on the series of events and the relations between them (Polkinghorne, 1995), striving to preserve the details and specificity of each case (see Flyvbjerg, 2006; Stake, 1995). Particular attention was paid to the sequence of representations that the designers shared (e.g. sketches and models), the stated reason for any changes made and their attitudes towards those changes, both at the time and in retrospect. The analytic objective was to develop coherent stories of the development process that were faithful to the collected research materials. Once the initial case write-ups had been produced, illustrated summaries were sent to the individual participants for comment, correction and approval. During thematic analysis (see section 4), the transcripts were subjected to an iterative coding process which included within-case and cross-case analysis to elaborate commonalities and differences (e.g. Eisenhardt, 1989; Fielding, 2001; Thomas, 2006). All three cases were coded independently by both researchers and then their codebooks were discussed, combined and refined into a single codebook (see Appendix). Particular attention was paid to the features of the cases that relate to discourse surrounding design creativity and fixation, both the list of themes emerging from prior case studies (see Crilly, in press) and wider discussions about the nature of idea generation and idea development. 


\section{Narrative analysis}

We present chronological accounts of the cases here: (1) the truss saw - redesign of the jewellers' fret saw to incorporate a truss structure in the frame; (2) the folding plugredesign of the British electrical plug to allow it to fold flat during transportation; (3) the suspended wheel - redesign of the bicycle wheel to incorporate radial suspension. Each case is preceded with a background statement that explains the history of the product category and the technical objectives and constraints that are relevant. The case is then described in detail, including quotations from the interviews and illustrations of the visual material required to understand the specific changes that were made during the design development.

Although the accounts were derived from verbatim transcripts that reflected pauses, broken sentences and repetitions, the quotations provided here are edited for ease of comprehension. Any other editorial additions or substitutions are enclosed in square brackets. Otherwise, the language used is entirely that of the participants. The images shown have been redrawn from the original case study materials for clarity and consistency. Some details are inevitably lost in this process, details that might be relevant to other interpretations (e.g. emphasising prototyping techniques, part modification and reuse, etc.). However, redrawing permits the most relevant design changes to be emphasised (typically structure, arrangement or operation of the products), changes which would otherwise be obscured (for example by variations in orientation, context or componentry).

\subsection{The truss saw}

This section describes the redesign of the jewellers' fret saw by Brian Meek of 'Knew Concepts' (see Figure 1, Knew Concepts, 2017). 


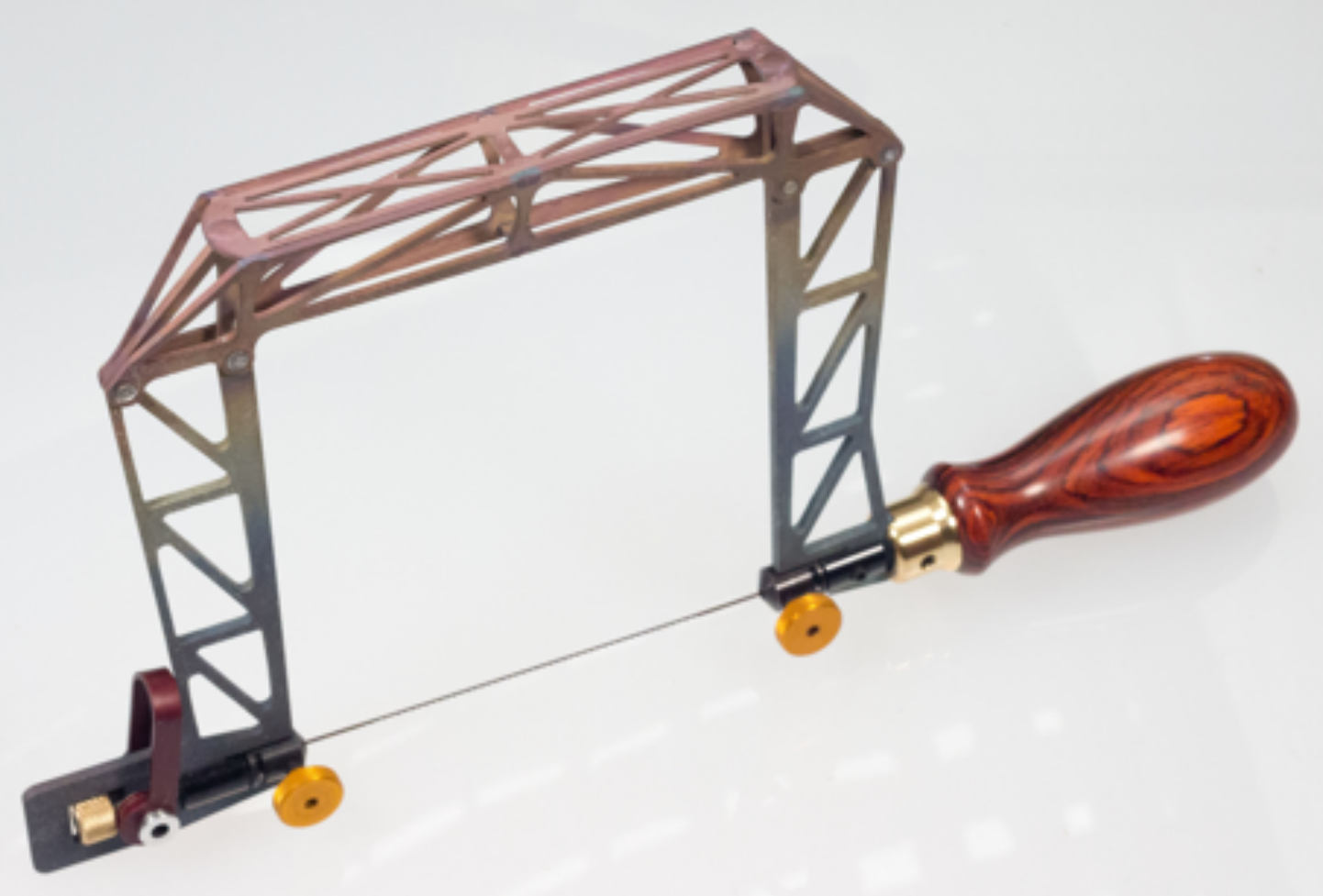

Figure 1. The titanium birdcage saw (five-inch version, special edition) designed by Brian Meek of Knew Concepts. Reproduced with permission. (c) Brian Meek.

Technical context: A fret saw is a hand-held saw with a fine string-like blade and a bowed frame (see Figure 2). Jewellers use fret saws to cut intricate patterns in metal and other materials. For the saw to be used accurately, the frame should be stiff (allowing the blade to be held under tension) and the frame should be light (reducing the torque applied to the user's wrist) (see Figure 3). The Knew Concepts 'Titanium Birdcage' fret saws employ twoand three-dimensional triangulated truss structures to provide a stiff, light frame. This is in contrast to other saws that continue to resemble a design that has remained largely unchanged since the 1800s. Note: Although we focus here on Brian Meek's design of the titanium birdcage saw, the story starts with the preceding products developed by Brian's colleague, Lee Marshall (as described by Brian).

Biographical sketch: Brian Meek trained as a metalsmith (BFA 1992, Syracuse University; MFA 1994, Cranbrook Academy of Art) and as a jeweller (Extended Studies Programme, 1991, City of London Polytechnic, now London Metropolitan University). He started his own company, Eisenring Enterprises, in 2008 to cover his various activities from making fine jewellery and jeweller's tools to graphic design, CNC programming and consulting. He has 
also taught jewellery for over 20 years. In 2010 he joined Lee Marshall to create the company that became Knew Concepts.

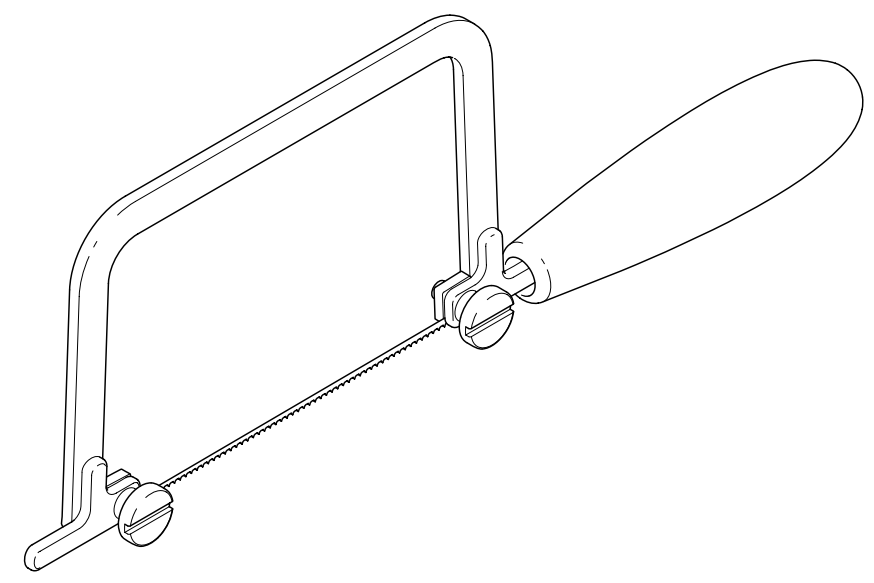

Figure 2. A traditional jewellers' fret saw with a bowed frame and a fine string-like blade. 

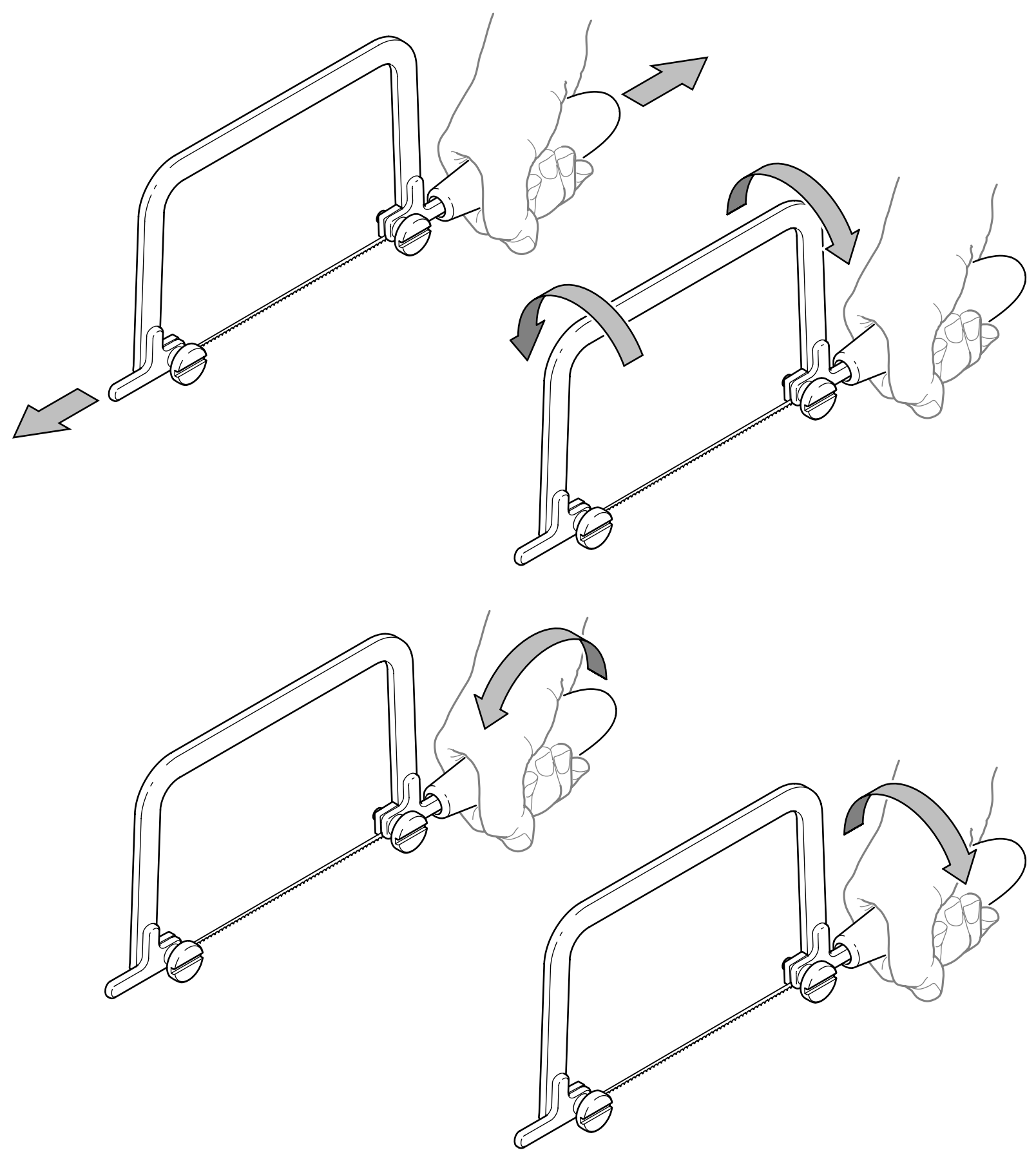

Figure 3. A fret saw should ideally exhibit good longitudinal and torsional stiffness to hold the blade tight and prevent it from twisting along its length (upper two images); the saw should also be lightweight so that the mass does not impose too much torque on the user's wrist (for example, as in the lower two images).

Lee Marshall founded Knew Concepts around the development of a new 'Precision Saw' for jewellers (see Figure 4). This is a hand-operated saw that is restrained by a guide to ensure a consistent cutting angle. The saw frame is made from sheet aluminium and is free to move vertically but is restrained laterally. One of Lee's customers was a jeweller who enjoyed 
using the new Precision Saw so much that she removed it from its guide and started using it for free-hand sawing tasks (using it as a fret saw). She liked the feel of the tool, especially the blade tensioning system. This was because the wide aluminium frame was stiff and thus permitted high blade tension to be achieved. She told Lee that he should develop the saw as a stand-alone tool, which he eventually did a few years later by simplifying the frame shape and moving the handle to be in line with the blade.

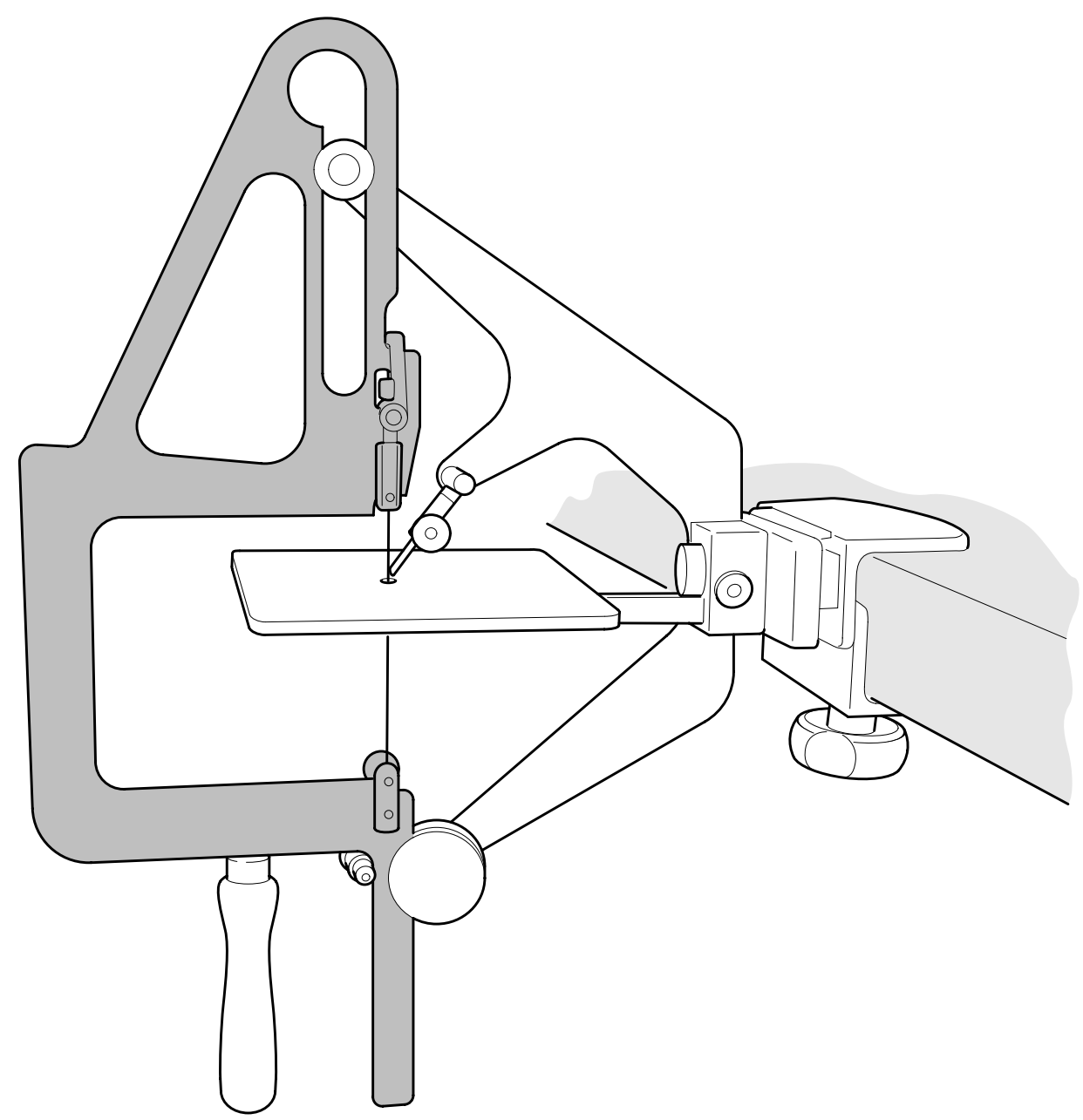

Figure 4. The Knew Concepts precision saw. The vertical guide clamps to the jeweller's bench and the jeweller moves the saw up and down to make cuts in the material that is held on the baseboard.

Lee then started finding ways of making the new prototype hand-held saw lighter. One of the solutions he tried was to drill lightening holes into the frame.

'The original one had rounded holes. ... He basically just drilled holes in, so they were all round, because he was doing them on a manual Bridgeport [milling machine]." 
Although the initial prototypes were hand-made, Lee later employed laser-cutting technology for shaping the frame. In doing so, he gradually 'squared off' the holes from circles to rounded quadrangles, allowing him to remove even more weight as there was less material surrounding the lightening holes (due to the more efficient tessellation of quadrangles within the shape of the frame) (see Figure 5).

'They [the holes] stayed that way [round] in the first few laser cut runs, just because that was the way he was thinking about it. After that they started to get square-ish because he realised he could wipe out the corners and get rid of more weight.' 


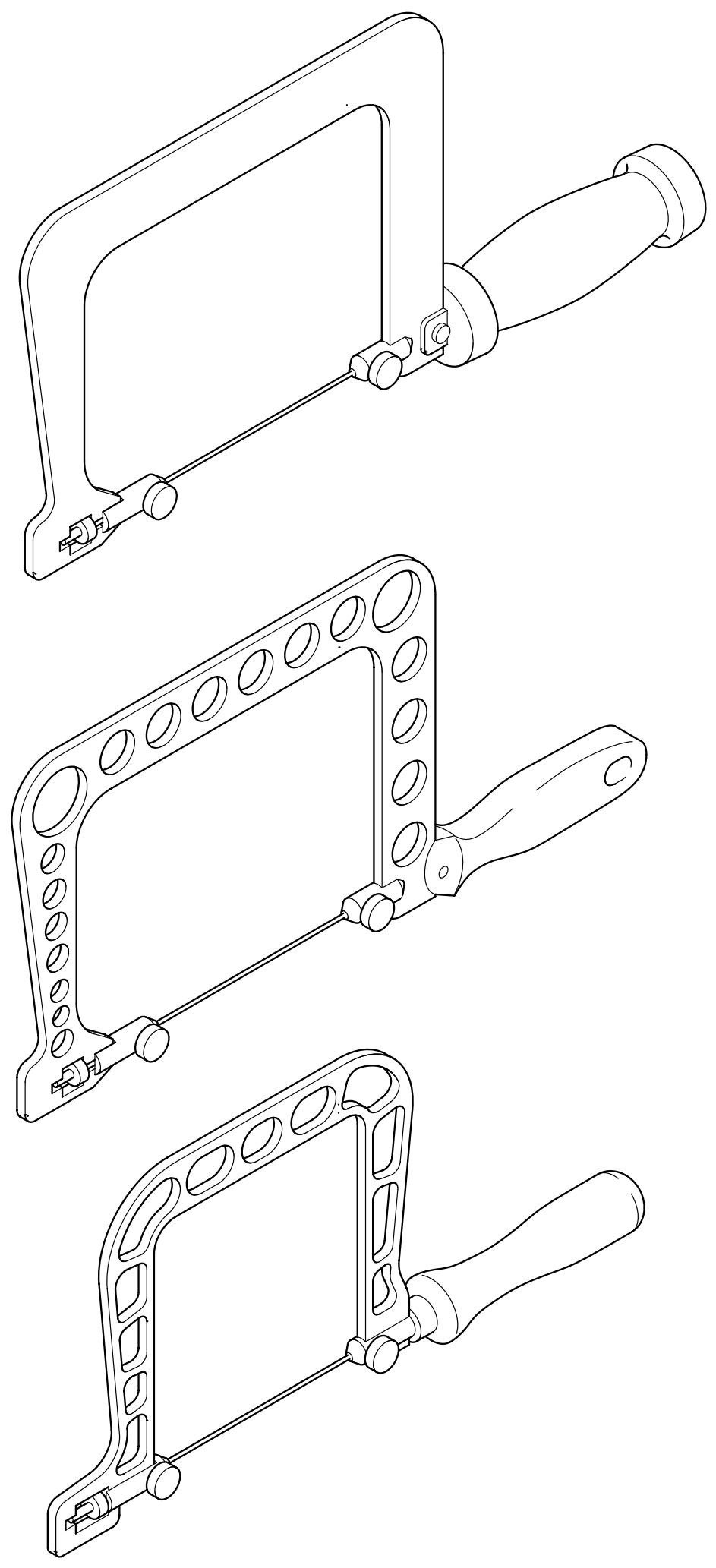

Figure 5. The evolution of the prototypes: the modified frame from the precision saw (top); the frame with circular lightening holes (middle); the holes reshaped to rounded quadrangles (bottom). 
The resulting fret saw became very popular with jewellers, woodworkers and other craftspeople. It was initially made in three sizes: three, five and eight inches (measured as the throat depth from the blade to the frame). Knew Concepts have been making and selling variants of this product since 2010 , continuing to improve the product incrementally over time.

'Because, especially in the early days, we were getting better, our manufacturing and our understanding of what the [saws] were was changing almost on a daily basis, so we were getting better and we kept just rolling the revisions in. The idea was we made the best saw we knew how to make today. Tomorrow, we may get better and we'll make it backwards compatible if we can.'

They had several attempts at implementing the squared-holes design to larger saws but they encountered additional challenges.

'The problem, traditionally, has always been that the deeper the saw gets, the more the leg is flexed, the sloppier the blades get, the less control you've got.'

They then developed a prototype for a twelve-inch marquetry saw (which is like a fret saw but bigger). During the development, Brian had an epiphany when an engineer suggested that for such a deep saw the shape of the lightening holes might induce racking (where structures distort by hinging at the connection between members), while a truss structure would limit that mode of distortion.

'I was staying with an old friend of mine who happens to be an engineer and he looked at it and said, "You know, you've got these square truss windows, you're going to get racking on them. Why don't you go to a full-on tension and compression frame?" I looked at them [the holes] and I said, "Yes, you're right. Okay, we can do that." That's pretty much where that [the triangulated truss] came from was him kicking me in the head. Somebody pointing it out to me. These [lightening holes] had developed from drill holes so we were thinking of them as lightening holes, not [the remaining material] as trusses necessarily. [...] "because you get so used to looking at it as, "These are holes," not, "These are trusses." Then as soon as somebody says something it's like, "Oh, yes, okay. Fix, fix, fix, done."”

The development of the large marquetry saw was not continued at that time, but reshaping the holes to leave a triangulated truss would have improved the performance of the saw. 
That said, the improvement would not have been great and might not have been noticeable to customers because of how stiff and light the product already was compared to traditional saws. In any case, the company already had a presence in the market and the visual appearance of the saw (including its squared-off holes) was important for their brand recognition (in fact, the company's logo continues to show a saw outline with squared holes to this day, see Figure 1). Any change to the product's appearance also required extensive interaction with retailers (e.g. updating product images for websites) and this administrative cost was something that the company tried to avoid.

'We didn't change the [...] saws because by that point they had become fairly distinctive and they had a presence in the market in their own form, and for three and five [the three-inch and five-inch saws] it doesn't make that much difference.'

In a separate strand of development, the company had purchased a quantity of titanium sheet from which they could cut saw frames that would exhibit better properties than their standard aluminium product. The material was discounted by the local supplier because the heat treatment had been performed in a way that was inappropriate for its intended military application. The saw frames were cut from this new material in the same way as for the aluminium product, yielding a high performance saw that commanded a premium price. It turned out that there was demand for the titanium fret saw and the product was a commercial success. However, when the company ran out of their discounted stock of material it was clear that they could not purchase titanium sheet at full cost without raising the product price to a level that would not be supported by the market. The main problem was how inefficiently the saw frame shapes tessellated onto a sheet of raw material, meaning that they were wasting a lot of that material. This wastage had previously not been too problematic because the material costs (aluminium and discounted titanium) had been relatively low; that would change if full-price titanium was now to be used. This was a problem that Brian focussed on.

Brian set about experimenting with making the saw frame from three separate pieces (two legs and the back) which could be more efficiently spaced out on the sheet material. The problem was then how to join the pieces together into a form that was sufficiently stiff. For example, a prototype was made with a two-piece back riveted to a pair of legs (see figure 6). 


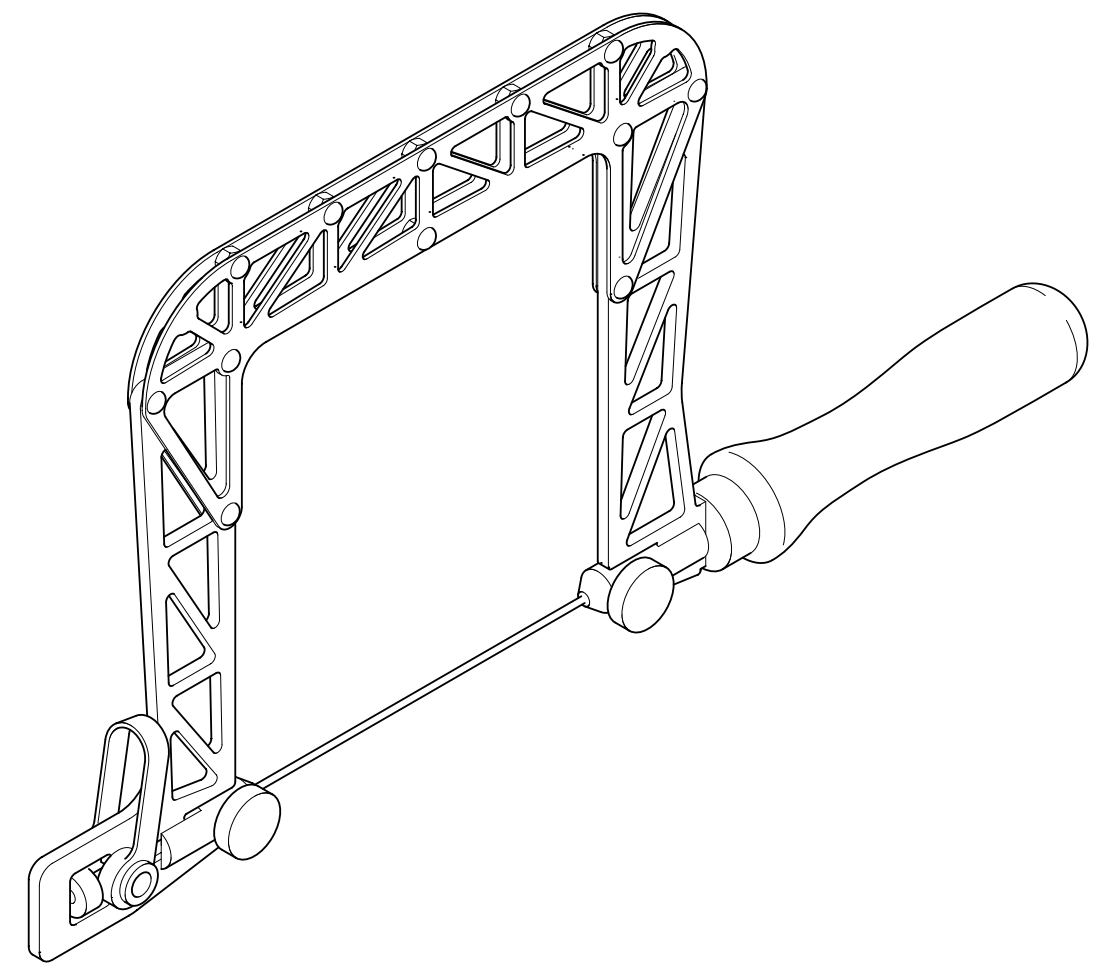

Figure 6. A prototype with a flat saw frame back (made of two plates) riveted to a pair of flat legs. Small nuts were used as spacers between the plates along the back of the saw.

'We tried for about six months to figure out some way to puzzle-piece a basically 2D frame together, with no luck. Most of those designs were rigid as hell in tension, but had no torsional rigidity at all. Spaghetti, in a word.'

Brian recognised the possibility to move the frame design beyond the flat two-dimensional sheet to incorporate three-dimensional components. This would increase stiffness, at the joints.

'I knew in the back of my head that a fully 3D truss would be much stronger, but the difficulties of welding $\mathrm{Ti}$ [titanium] on a (small) production basis are so dire that I didn't really pay much attention to it. ... Just too expensive (I thought) and problematic... 'proper' Ti welding requires a full inert-gas glovebox, which gets expensive. Ti welds done in air can get brittle due to atmospheric gas entrainment...'

All sorts of non-welded designs are investigated, including those with bonded joints and carbon-fibre. However, none of prototypes achieved the cost and performance requirements. Eventually, during an evening of tinkering, Brian tested out a three-dimensional truss option 
just because he was totally frustrated and wanted to see if the increase in rigidity would be worth all the problems that welding would bring (see Figure 7).

'I took some test parts that l'd been fiddling with one night. I got completely sick of looking at them, and bent them outwards to form the basis of the truss you see now [on the final product]. I've got a little tiny micro-TIG [Tungsten Inert Gas welder] at home. So, I was home fiddling with the thing, and zig-zagged a bit of Ti strip across the top as bracing, just to see what'd happen. ... Bingo! It didn't deflect at all, and a design was born [later named the 'titanium birdcage saw'].

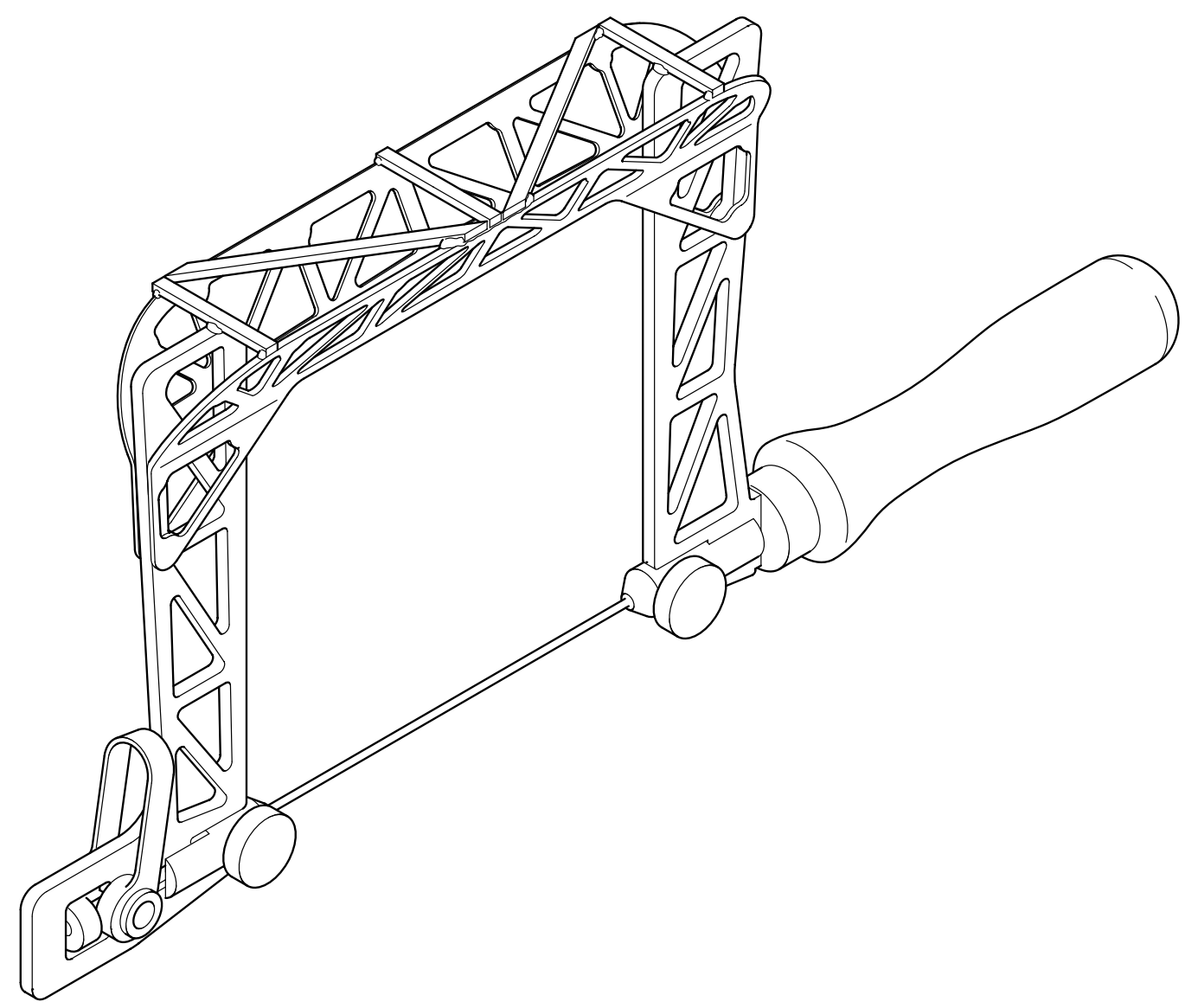

Figure 7. The first prototype saw with a three-dimensional truss for the back, connected to a pair of two-dimensional legs. Flat strips of titanium were welded in place across the top of the saw back.

This basic design was refined further by developing a top plate for the saw back and reducing its width to make the product look a bit more 'normal'. To assist with assembly, Brian implemented a tab, slot and rivet design for connecting the different components. 
'The tab, slot and rivet design I came up with actually works well from a production standpoint $[\ldots]$ it's self-jigging. You thread all the tabs through the holes, rivet the legs on, and the leg rivets hold the truss together during welding. The extra material on the tabs becomes weld filler, which saves fussing too.... We actually tried really hard to avoid 3D and welding as long as we could, because of the added expense, but it ended up being the only viable road forward.'

The intersection between the frame back and the frame legs is reminiscent of the constructions used in naval architecture (see Figure 8), a practice that Brian was aware of.

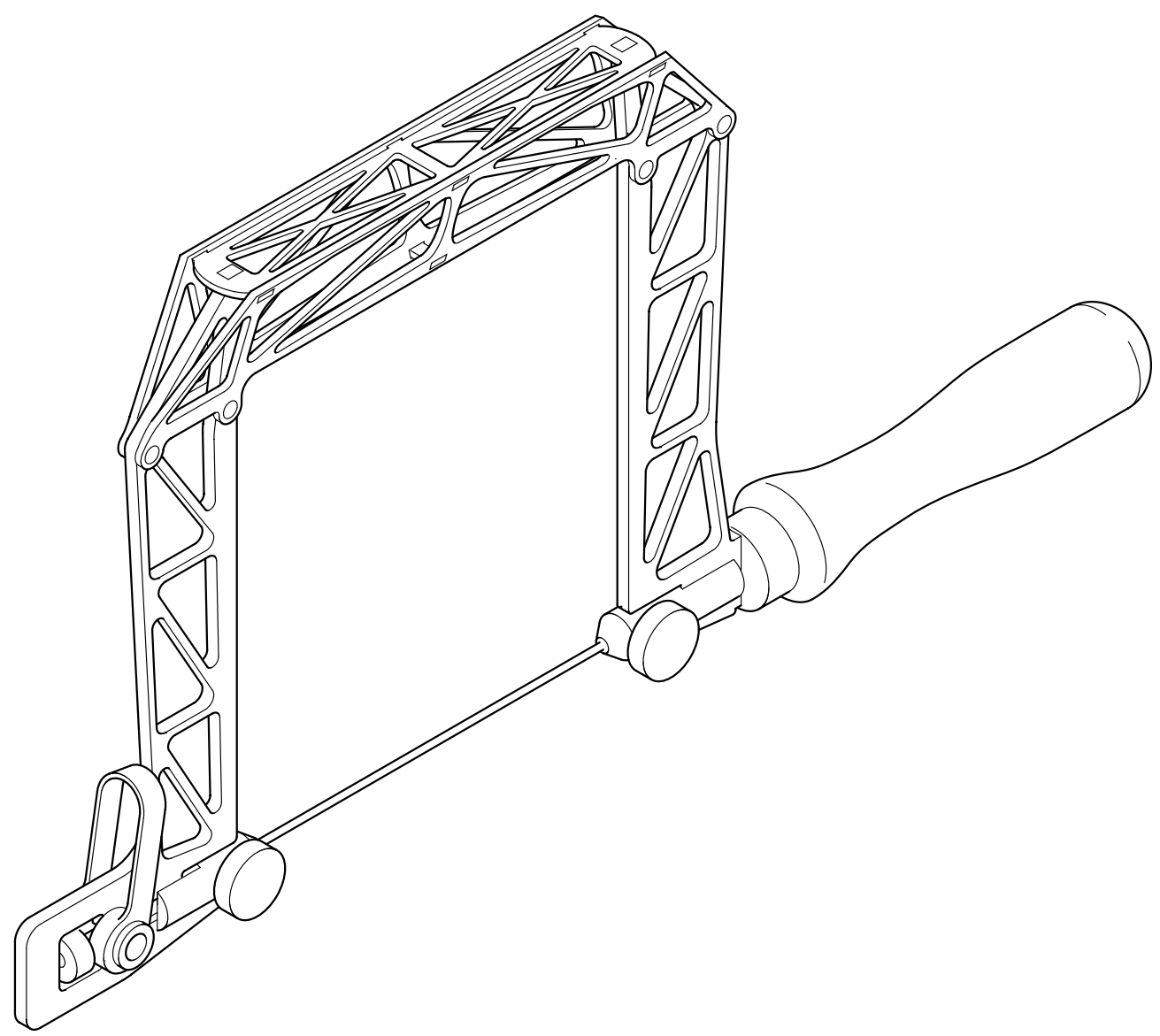

Figure 8. The tab, slot and rivet design of the final product makes component assembly easier. For example, each end of the saw back's top plate has a slot that accepts $a$ tab at the top of each corresponding leg (indicated by the small rectangles); rivets connect the legs to the spine (indicated by the small circles). This form of connection is similar (once inverted) to how the masts of a ship might intersect with the hull. 
'The design of the leg interlock, and the tabs owes a lot to me sailing square-riggers in my 20's. Look at it upside down: the legs are stepped into the keel of the truss very much the same way a ship's mast is stepped in, and the sides of the truss function as the shrouds anchoring the mast. It's mechanically akin to everything from a Viking longship, to HMS Victory. Funny how there really is nothing new under the sun.'

Brian had known about the possibility of implementing triangular truss structures in saw frames, since recognising the risk of racking effects in the marquetry saw. However, he explained that the triangulated truss structure would have been implemented on the birdcage saw even without this prior learning. The birdcage saw frame is designed as three main parts: two legs and the back. The legs are similar but not identical, and the back is made up of two identical side plates and a top plate. Any weight savings achieved in the design of one part get multiplied through the other components. With so much reward for any small weight saving, Brian described the triangulated truss as an inevitable design evolution. (Note that although the part count increased from the original one-piece design, those parts tessellate well and the material is used more efficiently as the three back parts are made from thinner material stock).

'Part of the design process for the Birdcage [...] was [that I was] chasing grams out of this thing [the frame back] by the end, because it's at the end of a cantilever [the legs, and therefore the mass matters a lot]. The truss was designed in halves, so I'm working on this [half], but every extra little bit that l've got in here [gestures to geometry] or in here [again] is also down here [gestures to repeated geometry] and is also on the backside in both places, so there are four of [those] at the end of a beam at the exact wrong place [at the end of the cantilever]. So sooner or later I would have tumbled to, "Oh, yes, you've got to make them a truss if you're going to make them as light as you can." Because really what this is is a Pratt truss, and it's kind of heavily modified but it started out as a Pratt truss. I would have tumbled to that one way or the other just as a function of chasing the weight out.'

The birdcage saw frame combines a back design that is a three-dimensional truss with a leg design that is a two-dimensional truss. This raises the question as to whether a fully threedimensional truss (not just the back, but the legs also) would be even better technically, and also be a commercially viable product. In fact, a fully three-dimensional truss frame was trialled on a large marquetry saw design but not pursued any further. 
'we did know of the problems ... associated with Ti welding, and wanted to avoid them at all costs, while we were unsure whether there was enough benefit to a 3D truss to be worth the bother. It turned out that it was. But not enough that a fully 3D frame with 3D joints was worth doing more than [just] exploring.'

To complete the story, once the titanium birdcage saw was already a success, and the truss structure was accepted by the market, a new version of the flat aluminium saw was launched. This heavy-duty version featured a triangulated truss structure refined with computational design tools and was capable of much higher blade tension than the preceding models.

\subsection{The folding plug}

This section describes the redesign of the British electrical plug by Min-Kyu Choi of 'Made in Mind' (see Figure 9, The Mu, 2017).

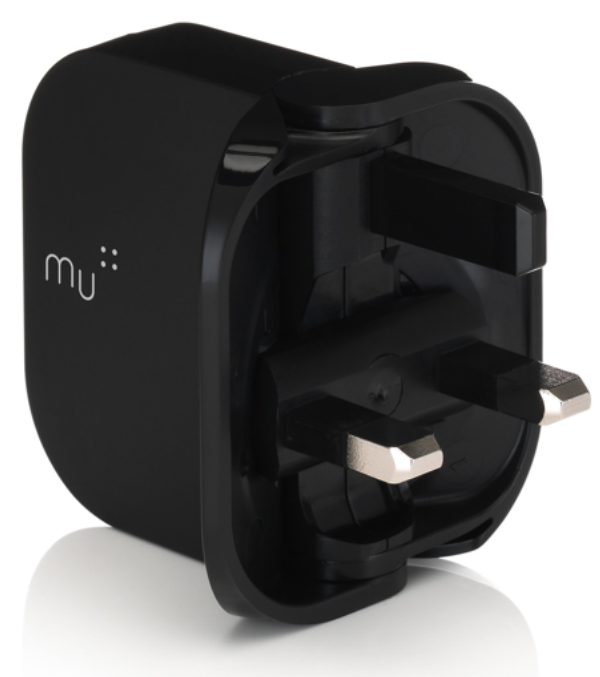

Figure 9. The 'mu' folding UK charger (tablet version) designed by Min-Kyu Choi of Made in Mind. Marketing image from company website:

https://www.themu.co.uk/collections/collection/products/mu-tablet-black (accessed 19th July 2018). Reproduced with permission. (C) The Mu.

Technical context: The current British three-pin (rectangular) plug is defined by British

Standard 1363 (see Figure 10). This standard precisely specifies the dimensions of the three plug pins and their relative arrangement. A plug that interfaces with the British electrical 
socket must conform to these geometric constraints. Prior to the account described below, the British plug had remained largely unchanged since the 1940s (see Peacock, 2013).

Biographical sketch: Min-Kyu Choi studied Graphic and Media Design (BA 2007, University of the Arts London), followed by Design Products (MA 2009, Royal College of Art). It was on that course that he first arrived at the idea for a folding plug. He subsequently, co-founded Made in Mind to develop the product further. In 2012 he founded Design Narrative with a focus on developing other products (see Royal College of Art, n.d.).

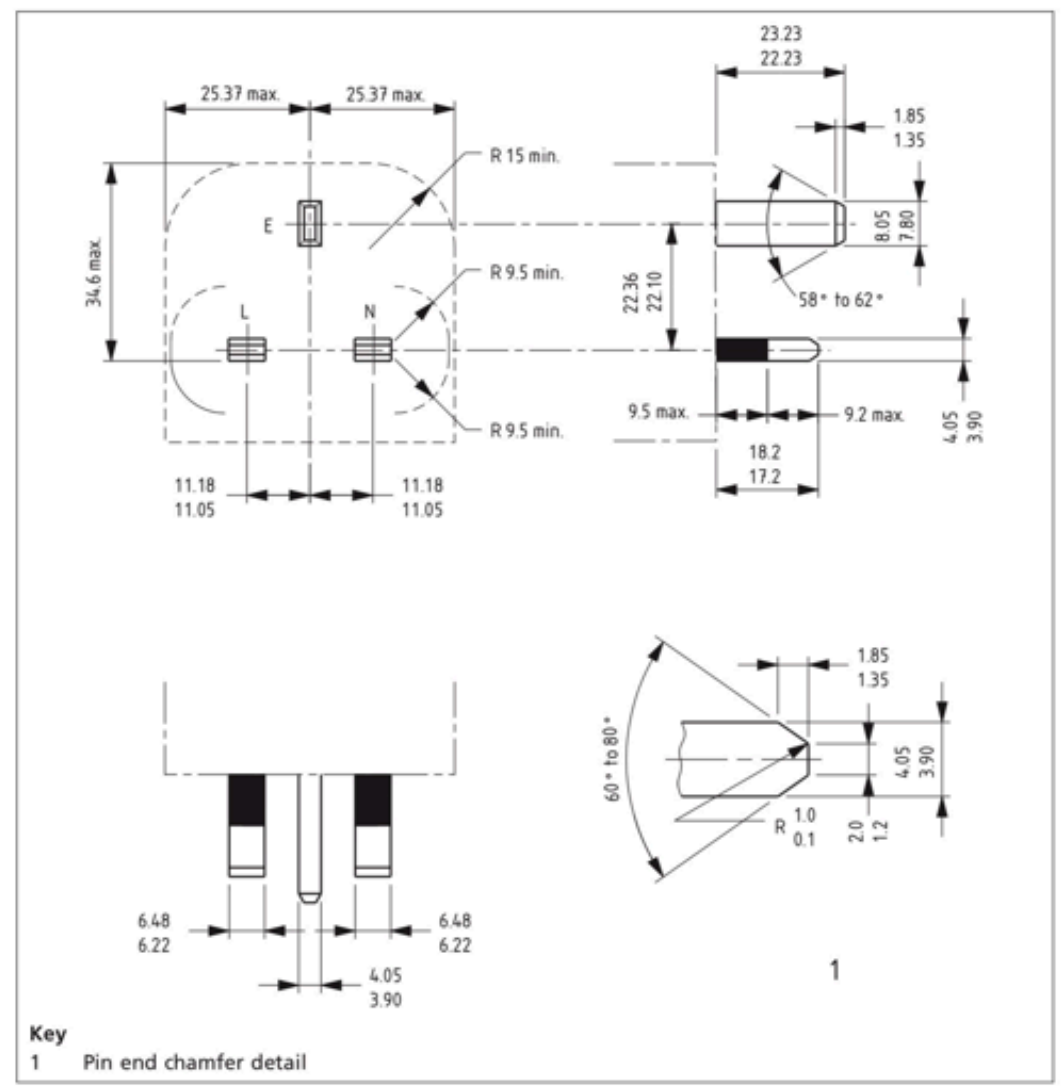



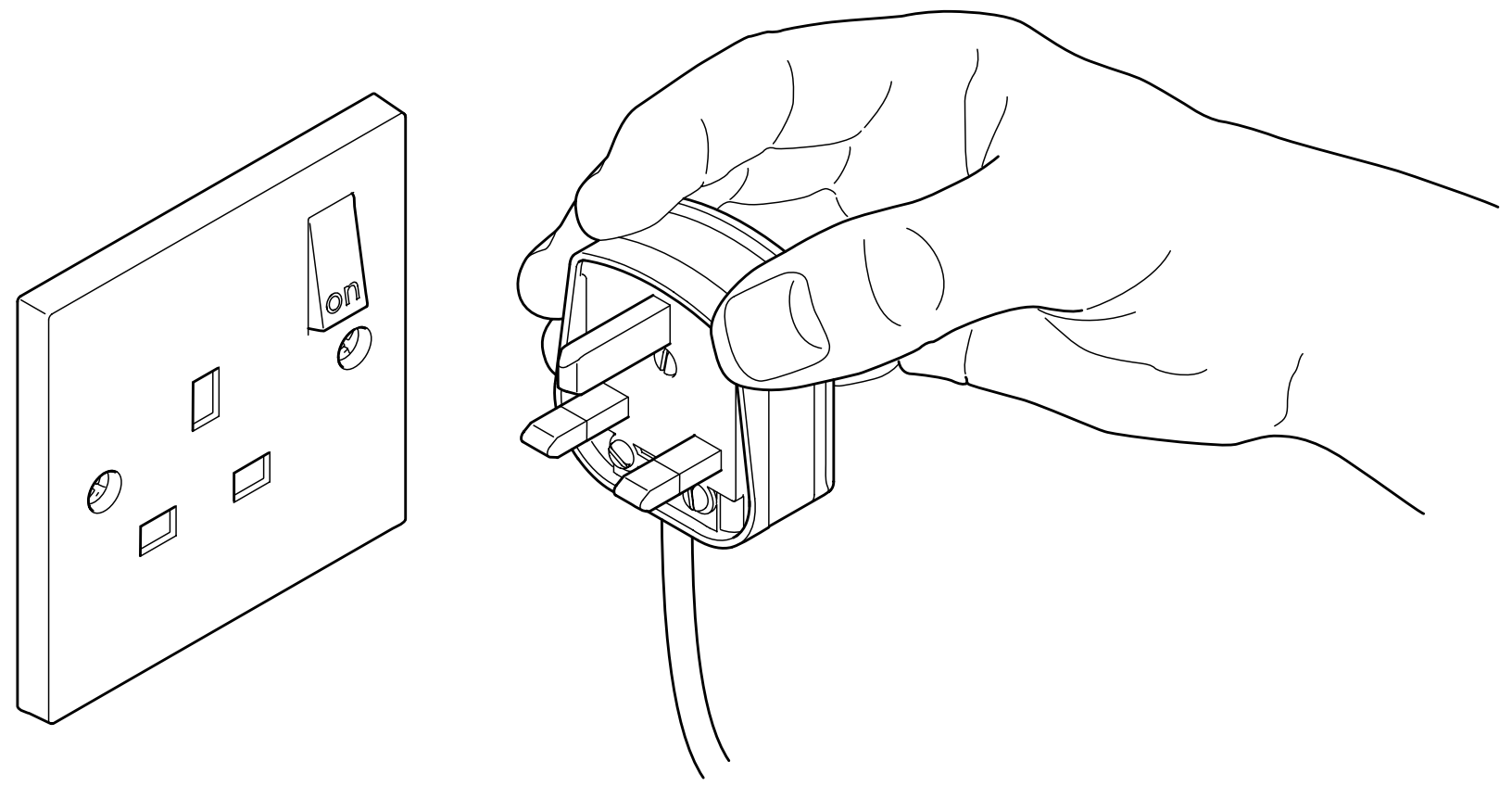

Figure 10. Top: The pin geometry of the standard British electrical plug is defined by BS 1363 (The British Standards Institution, 2016: p. 42, dimensions are in $\mathrm{mm}$, image used with permission of BSI). Bottom: An example of a standard British electrical plug and socket, illustrating their size relative to an adult hand.

As a student in product design, Min-Kyu carried his laptop to college every day. The laptop was new and slim, but it came with a bulky UK plug. One day, to his frustration, he found the laptop scratched by the plug. A few months later, he was given a project brief for solving a simple, daily life problem. He immediately thought of his scratched laptop, and he set off to solve the problem of the bulky plug design.

At first, Min-Kyu searched for the existence of a product that solved a similar problem and then looked at the relevant standards and regulations. He sketched some ideas for different ways to allow the plug to change shape. In doing so, he came to understand that the main thing that needed to stay the same was the configuration of pins when the plug was in use.

'I realised that there are standards that I can't change whatsoever. So, first I articulated what I can possibly change in the standard regulation. Obviously, the form and shape of the pins, and their [arrangement] cannot be changed. So, I just removed all of the main body of the plug. Then I just played around to make it slim and small, with a transforming method: disassemble, rearrange, twist, fold, etc. Then I drew all the feasible options, and I made a user scenario. Through the scenario, I realised a clue [to the] requirements: the plug should be able to transform [to 
become] slim and small within three steps; the plug must not disturb or damage other stuff when it is in a bag or pocket; usability of the product must not be [worse] than a conventional plug. In the end, the most viable solution was [the] folding design."

In looking at different ways in which the plug could be manipulated (e.g. squeezing and stretching, assembly and /disassembly, folding and twisting), Min-Kyu focussed at first on the pins. He then started thinking about how to package other components, such as the fuse, and how the plug should be grasped during insertion and removal from the socket. If the plug was to fold to become smaller during transportation then it would still need to be sufficiently large to grip when being handled.

'So, I ignored all other elements, I really focussed on transposing the pins at the first stage. After I decided the pins' transposing direction, I gradually built up other elements such as hinge mechanism, fuse location, protecting structure for pins, handle and hinge. First, I determined the structure and position of the hinges for the pins, which is an important factor that enables pin conversion. And I relocated the fuse [to avoid] the hinge area; then I built the wing parts and its hinges. Finally, I noticed the concept of the plug is too slim to have a proper grip to hold. So, I added a handle feature, like a tea cup's handle.'

After exploring a variety of folding and twisting options, Min-Kyu arrived at a design in which the lower two pins (Live and Neutral) twist through 90 degrees to become correctly arranged relative to the upper pin (Earth). A pair of side 'wings' were added to enclose the pins when folded and to present a flat surface to the socket, limiting the depth of pin insertion. To unfold the plug the user had to first open the two side wings - which opened from back to front and then to rotate the pins (see Figure 11). The initial prototypes of the foldable plug were made by a combination of 3D printing and hand tooling. The first prototype showed how it would be possible to fold the plug; for the second prototype Min-Kyu considered the mechanical strength and the wall thicknesses of the various components. 

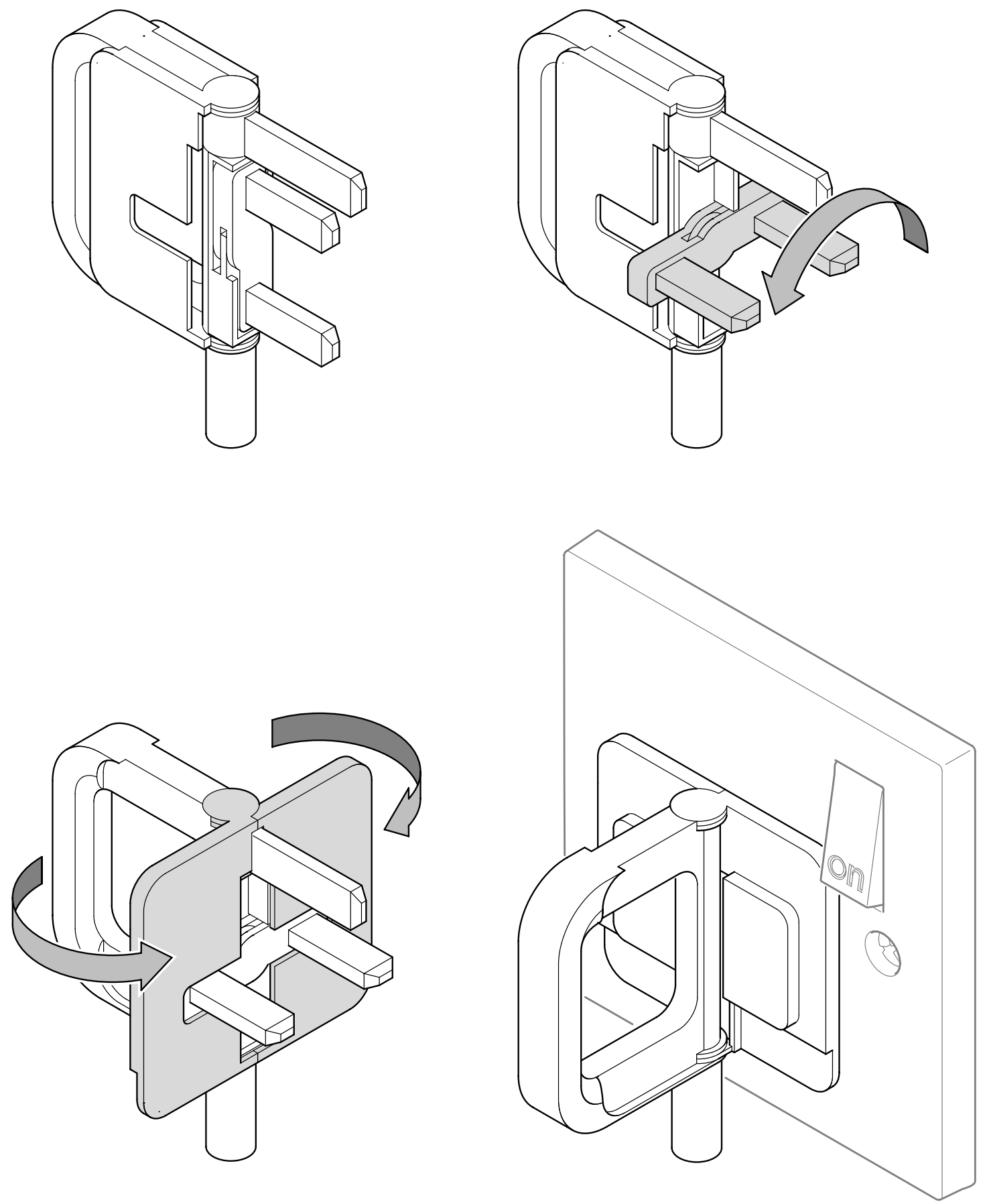

Figure 11. The first prototype folding plug, with a fixed Earth pin, rotating Live and Neutral pins, and a finger loop ('wheel') to assist with removing the plug from the socket. The sequence of operation runs from top left to top right, then bottom left to bottom right.

During this process of design development, Min-Kyu identified other beneficiaries of the folding plug concept beyond the end user. 
'And during that time, we realised that this portable folding concept is not only beneficial to customers but also the manufacturer and the OEM [original equipment manufacturer] customers such as the mobile phone manufactures. [... It] means they can reduce the packaging size and they can save [costs on] logistics and storage, etc.'

He also started looking at the consequences of having a folding plug, and the additional opportunities that would result.

'So, after I finished this [prototype], I just [thought] "If it's foldable, then what other benefits can I make?" [...] I wanted to add more benefits [for] that feature.'

Min-Kyu conducted research into user behaviour with electrical plugs and he also studied the environments those plugs are operated in. In doing so, he observed that many people use converters to generate multiple outlets from a single socket (sometimes called 'multi tap' or 'multiple gang') and that there was increasing use of integrated adaptors for charging mobile devices.

'So, this was the idea, to make it a simpler multi tap. [...] During the development, I realised that a lot of people use adapters, not only plugs. Because most of the modern mobile products [are] low power products, so they use adapters [with built in plugs] rather than [power cable] plugs. For the mobile phones or iPads or whatever they are.'

From these insights, Min-Kyu created models of a compact multi tap converter capable of accommodating the plugs in their folded state and also a newly-designed folding USB adapter (see Figure 12). 

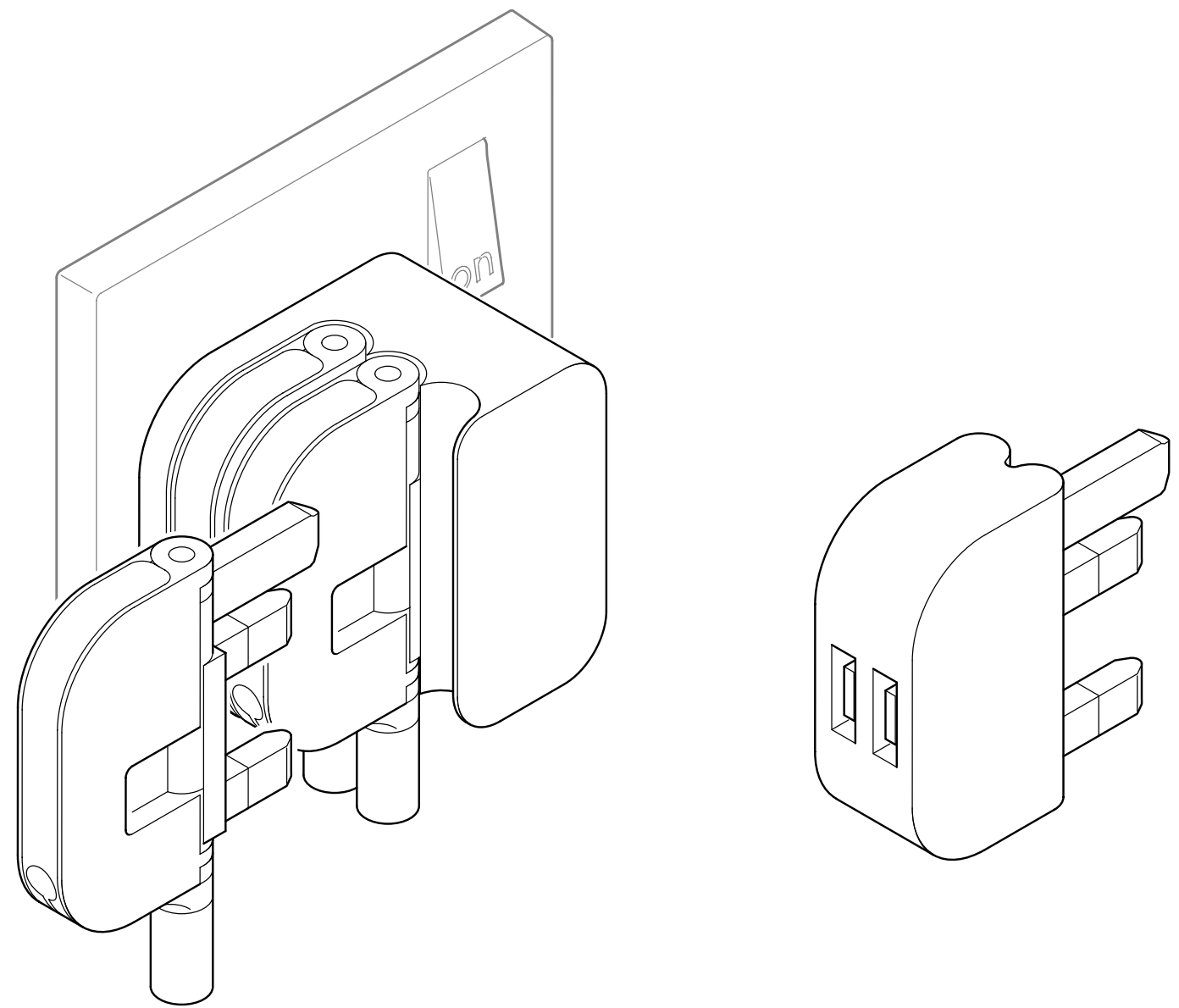

Figure 12. The folding plug concept showed the way for other product ideas, including a multi tap converter capable of accommodating the plugs in their folded state (left) and also a folding USB adapter (right). Note that these product options are here represented as a derivative of the third prototype (see Figure 10).

By this point, Min-Kyu had developed a third prototype that better represented how the product might appear once manufactured. He exhibited this at his college's end of year show. During this event, he noticed that many of the people who interacted with his plugs attempted to open the wings first rather than rotating the pins first. Opening the wings first was possible, but it then prevented the pins from being rotated, rendering the plug inoperable unless the user performed the reverse sequence of manipulations and started again by rotating the pins first and then opening the wings (see Figure 13). When Min-Kyu observed this repeated behaviour, he realized that the plug was not intuitive to unfold and told himself that the next prototype should address this issue. 

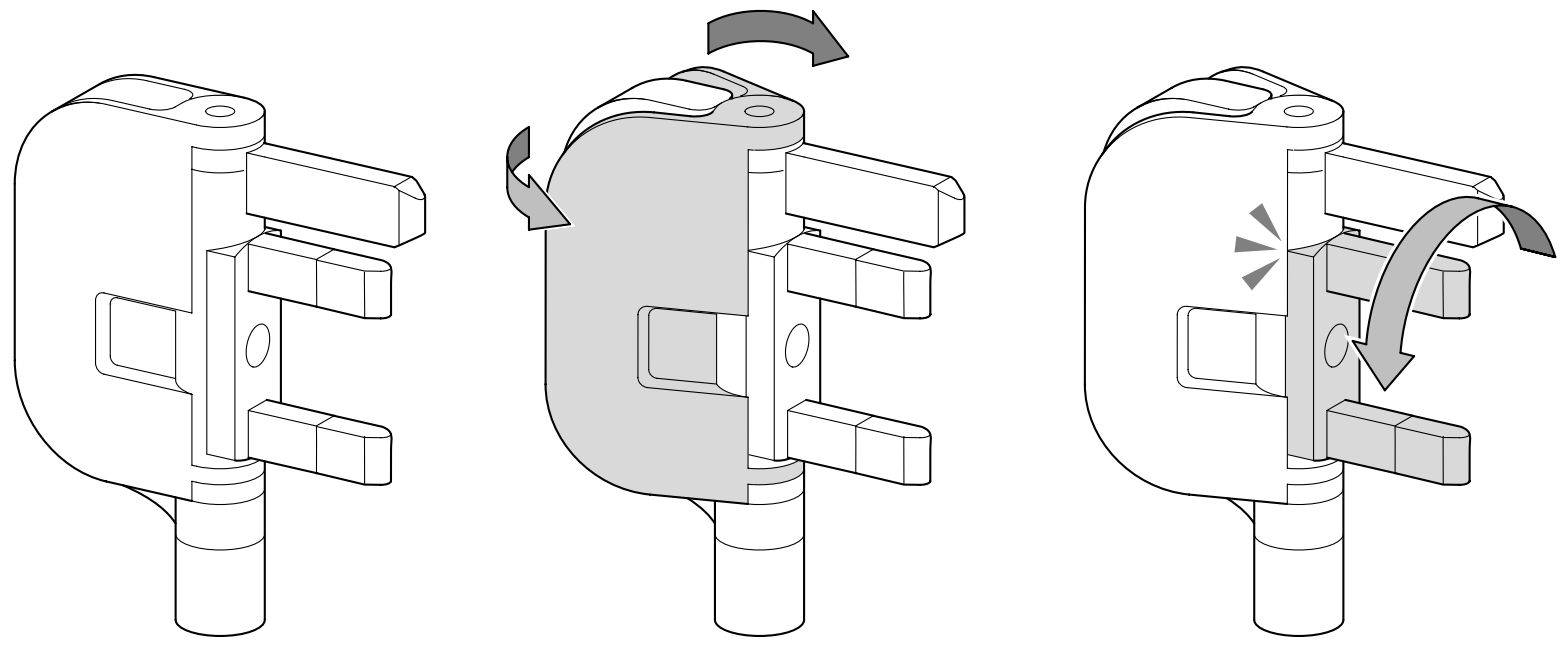

Figure 13. The third prototype folded flat just like the earlier ones (left). Min-Kyu observed that users tried to open the wings first (middle) but this then prevented the pins from being rotated (right).

The initial reason Min-Kyu designed the product with the wings opening from back to front was because he wanted the opened wings to provide a flat surface on the front of the plug, similar to the appearance of the traditional plug.

'I didn't want to make a geeky product. I tried to keep the image of the [traditional] plug as much as possible for users who are already familiar with the existing plug. Even if [the product has] got a useful feature, if a user feels it's awkward [then] I would think there is a design problem.'

For the next step in developing the product, Min-Kyu obtained funding from an organisation acting as a 'design-led start-up incubator'. He began thinking of how the product could be commercialised, and he researched several possible markets. He soon realised that the new design would be hard to sell as a plug in itself. This was because power cable plugs are a business-to-business product, and the big electronics manufacturers would not take the risk to replace the plug on their products with an unproven concept. Min-Kyu thought that because integrated adapter plugs (rather than power cable plugs), are a business-toconsumer product, they would be easier to commercialise. Attention was then switched to developing an adapter variant of his folding plug concept and the folding power plug variant was never marketed.

Once he had decided to develop the adapter, Min-Kyu started looking at the electronic components that would now need to be accommodated. He gradually accepted that his 
current design was too slim. As such, the next revision had to address two problems: that of making the plug intuitive to unfold; and that of fitting in the necessary electronic components for an adapter.

'It didn't really take a long time to drop the original concept, once we'd decided to make an integrated adapter plug rather than a power cable plug. [This was] because somehow we needed space for electric components. And also, I [was] concerned with the problem which [arose] during the final year show from the users. So I just put these two things in my mind, that "these are issues that I have to update in the new version".'

The main change in the design of the plug's body was to reverse the direction of the wings, so that they would open from front to back. This would act to shield the pins until the wings had been opened, preventing any confusion over the correct sequence of operation. Another benefit of this change was that the wings would now act as an extra level of protection between the adapter pins and anything that they might scratch or damage. However, this design meant that it was not possible to have the pins protruding from a flat face during use, as would be expected with a traditional plug. For this reason, Min-Kyu was initially unsure of this new design, and he kept it back as 'Plan B', while he spent time trying to find some other ways of solving the problems with the initial design. However, after a month of tinkering, he switched to 'Plan B' and adopted the design with wings folding in the reverse direction (see Figure 14). 

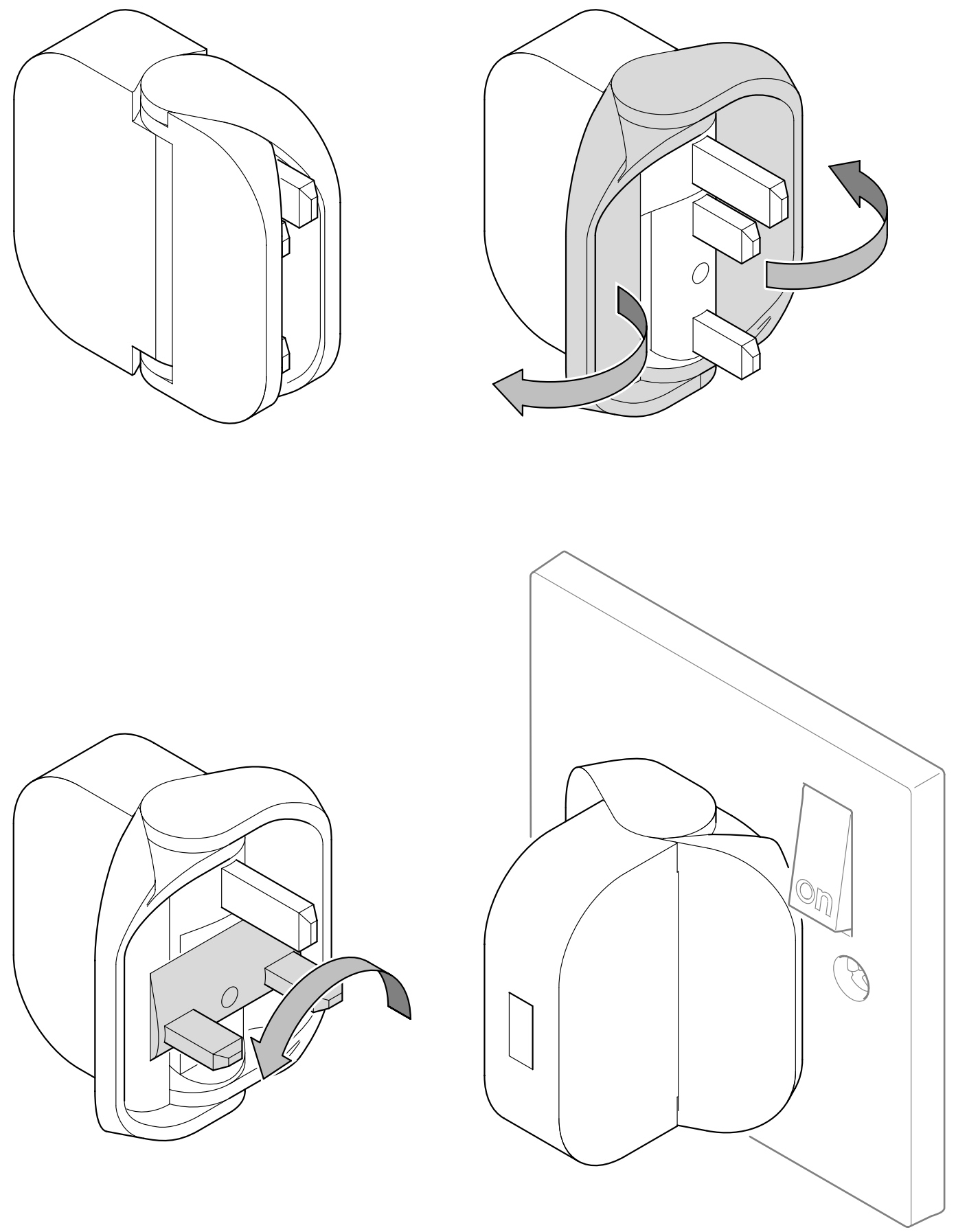

Figure 14. The USB adapter design with revised sequence of use: wings open first, revealing the pins, which can only then be twisted, permitting insertion into the socket.

At the point that this design change was made, Min-Kyu had been thinking about the folding plug idea for a couple of years and working on the design of it for a few months. However, he describes the change as one that was easy to make. 
'Changing that concept [...], wasn't that difficult at all, but I spent more time to keep that [initial] design. Actually, I already had [the] "Plan B" option [at] an early stage which was to change it from here [wings open from back to front] to here [wings open from front to back]. But I preferred [the] "Plan A" option which [was] trying to solve the problem without changing the initial design.'

Although the new design satisfied some technical objectives (e.g. usability, pin enclosure), some more subjective criteria (e.g. aesthetics, familiarity) were sacrificed.

"It's again, compromised. [l also realised] there's a way to make the earth pin retract into the main body and [have it] only pop out when unfolding the plug. In that case, you would add components and also more parts, more cost. [It was] possible, but I compromised.'

The resulting design led to Min-Kyu's first commercialised product. The folding USB adaptor is still available for sale, now accompanied by an adaptor with dual USB output and a travel version suited to different international socket standards.

\subsection{The suspended wheel}

This section describes the redesign of the spoked wheel by Sam Pearce of 'Loopwheels' (see Figure 15, Loopwheels, 2017). 


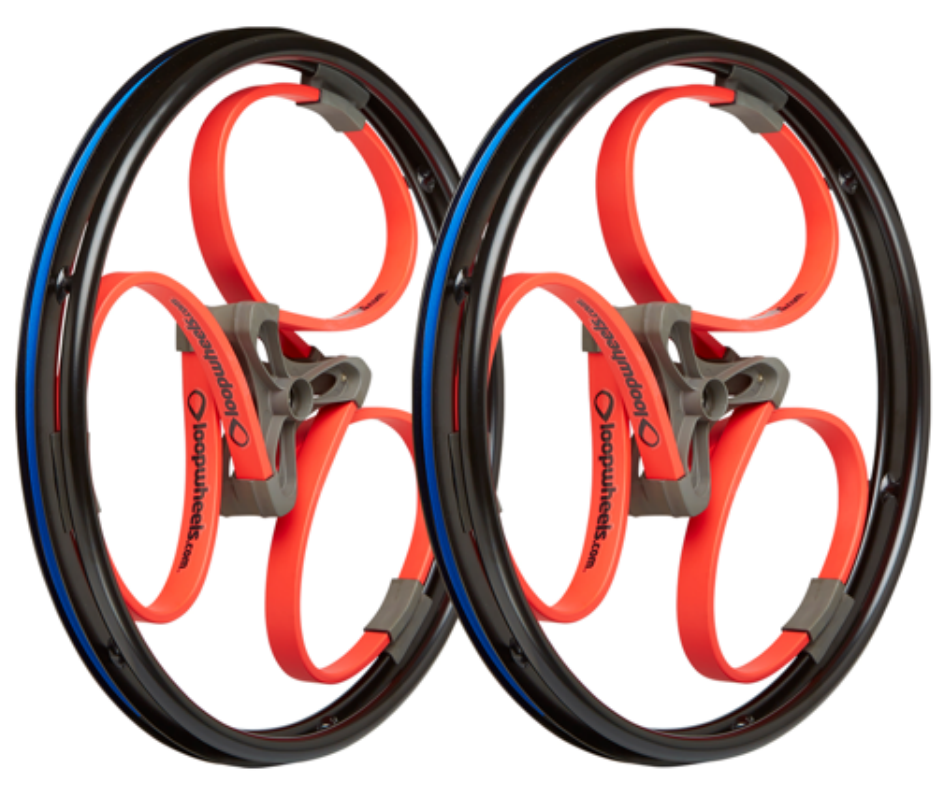

Figure 15. A pair of 'Loopwheels' with radial suspension (wheelchair version) designed by Sam Pearce of Loopwheels. Marketing image from company website: https://www.loopwheels.com/wp-content/uploads/2015/10/red-pair.jpg (accessed 19th July 2018). Reproduced with permission. (c Loopwheels.

Technical context: The Loopwheel product offers integrated radial suspension. This permits the inclusion of suspension on vehicles for which it would otherwise be difficult to house a conventional suspension system, such as wheelchairs and folding bicycles. Prior to the account described below, the bicycle and wheelchair markets were dominated by a spoked wheel design, originating in the 1800s. For a suspended wheel to be efficient and comfortable it must do three things: it must permit in-plane movement of the hub relative to the rim, referred to here as 'radial compliance'; it must resist out-of-plane movement of the hub relative to the rim, referred to here as 'lateral stiffness'; it must resist rotation of the hub relative to the rim about the wheel's axis, referred to here as 'torsional stiffness' (see Figure 16).

Biographical sketch: Sam Pearce studied Mechanical Engineering (BEng, 1990, University of Leeds) and Industrial Design for Engineering (MA, 1993, University of Teesside). For twenty years he worked as a designer in the medical and computing industries and as a design consultant specialising in three-dimensional folding mechanisms. At the time when he had the initial idea for a radially suspended wheel, he was designing a pushchair for a company based in The Netherlands. 

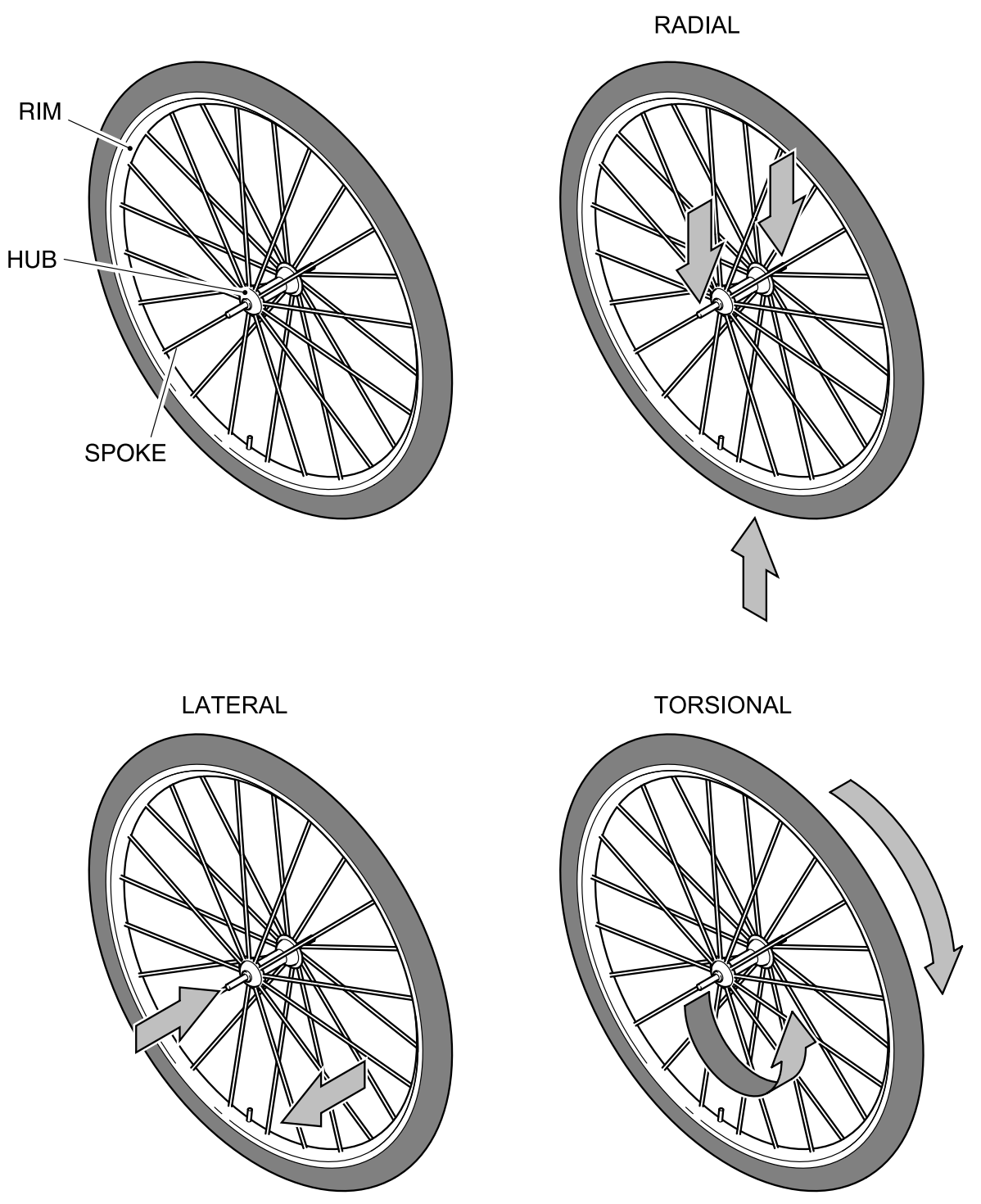

Figure 16. The conventional spoked wheel (top left), and three kinds of loading it is subjected to. The wheel should be moderately compliant under radial compression to provide comfort (top right) and yet should resist lateral forces, such as during cornering or pedalling out of the saddle (bottom left) and torsional forces, such as during braking and acceleration (bottom right).

In 2007, Sam was a consulting designer with a specialty in three-dimensional folding mechanisms. One day, he was sitting in an airport when he observed a child almost being jolted from a pushchair when the front wheels hit a bump. He wondered why the wheels couldn't offer suspension in all directions in the vertical plane. He 
sketched an initial idea for the solution, with three leaf springs connecting the hub to the rim (See Figure 17).

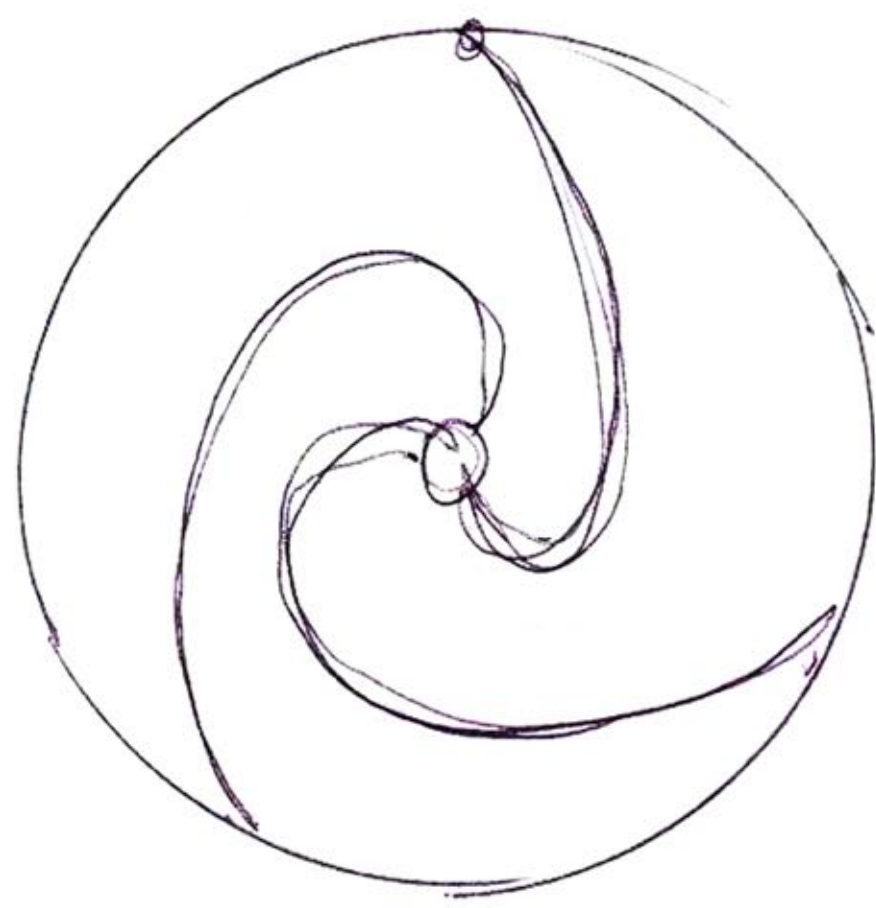

Figure 17: Sam's initial notebook sketch of the radial suspension wheel showed the hub connected to the rim by three leaf springs. () Sam Pearce. Reproduced with permission.

This sketch remained in Sam's notebook for two years before he looked back at it and finally made a model out of the materials he had to hand, including pieces of guttering and plywood (see Figure 18). This very first prototype was made at an appropriate scale for a pushchair wheel, which was consistent with his initial inspiration and also the work he was then doing for a pushchair company. When he proposed his new wheel design to the company, it became clear that that product category would not support the cost of a suspended wheel. In addition to making the wheel work technically, Sam would have to carefully consider the right application for the technology. 


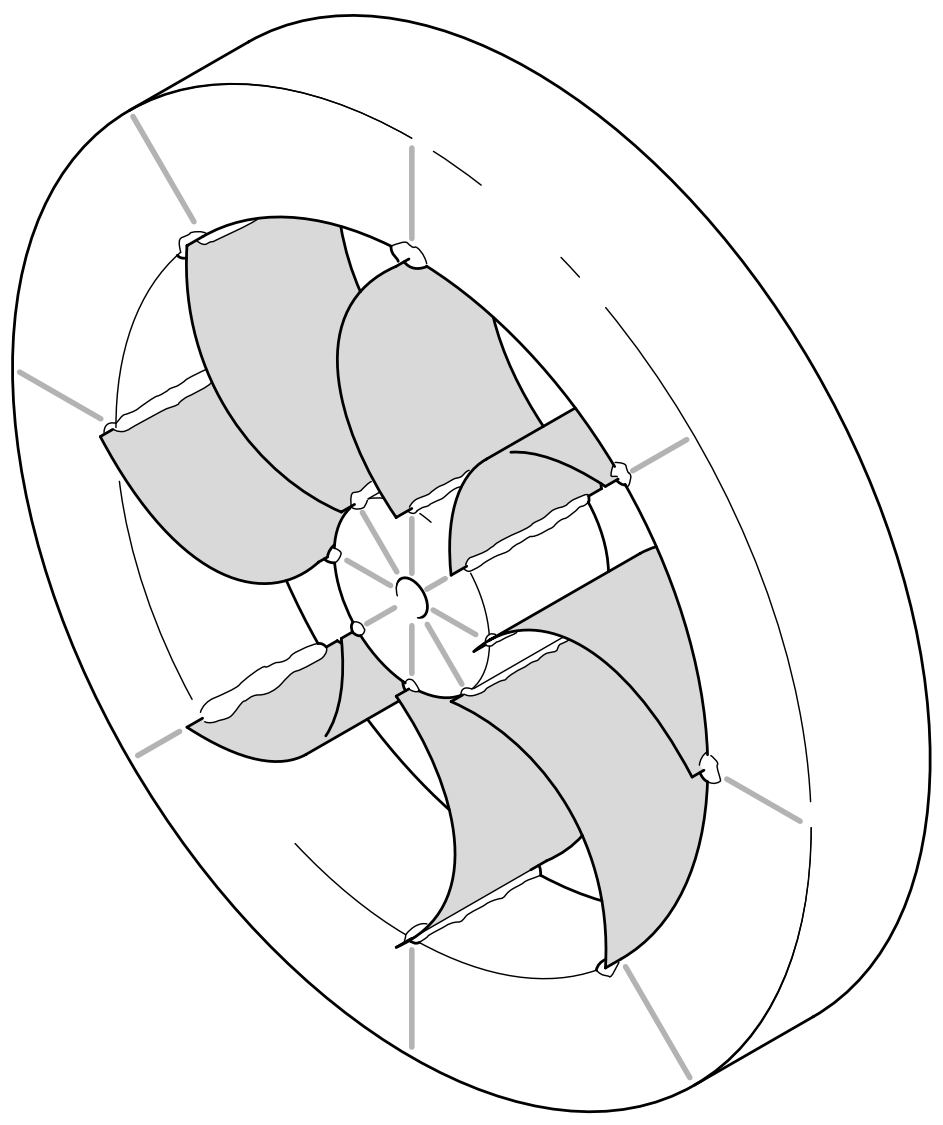

Figure 18. Sam's first prototype of a suspended wheel (approximately nine-inch diameter), with the hub connected to the rim by eight springs. The hub and the rim were cut from plywood and bonded to the springs which were sections of plastic guttering.

'So, a great idea, but we needed it to be injection moulded and [only cost] two Euros [per wheel]. It's not important enough to a mother or father, it's actually the cosy internal or a pocket for their mobile phone that is much more important than the suspension in the wheel. [...] If you get this right it can go on any application, but you've got to be careful which application you pick.'

As he was riding mountain bikes at the time, Sam thought that he would be able to test that size of wheel on his own bike and use the feedback to keep improving his prototypes. His first 26-inch wheel prototype for this application used a set of eight springs arranged in pairs (see Figure 19). This replaced the spiral design from his initial sketch, but still had the springs meeting the hub and rim obliquely.

'That first one I was able to ride, but not really. I could just about ride it in a straight line. If you imagine riding, it was like a piece of jelly really. There was no lateral 
stiffness, it's pinned. It's got too many pins, we've got too many directional movements. So, under-constrained, a wobbly wheel really.'

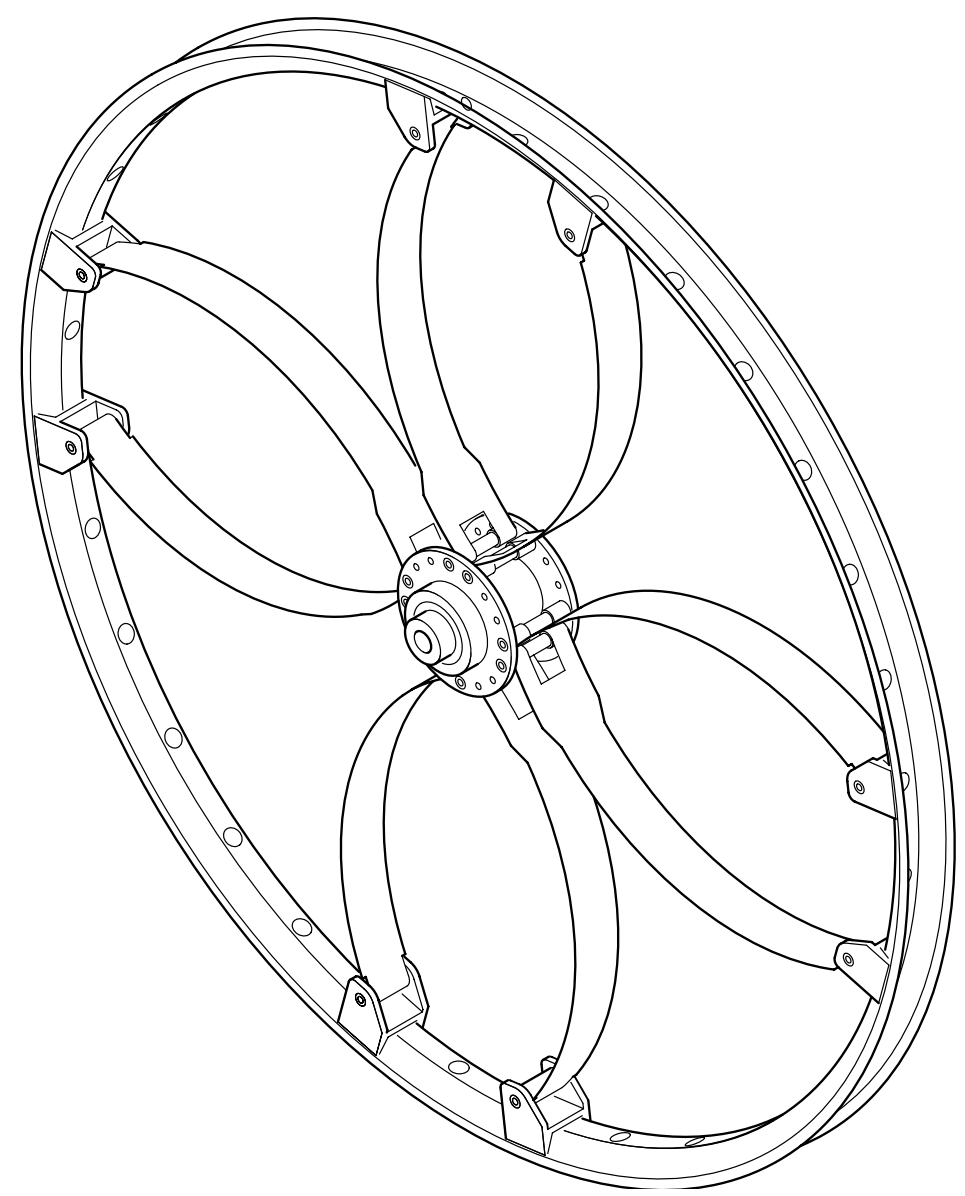

Figure 19. Sam's first 26-inch prototype wheel, with four pairs of steel spokes/springs, pivoting at the rim and the hub (both of which were standard parts).

Having already worked with plastic, steel and plywood springs Sam then started thinking about using carbon composite. He contacted a local manufacturer who specialized in these materials and in collaboration with them made his first wheel prototype using carbon springs. This time, rather than arranging eight springs to create four loops, he made four continuous loops, each using only one curved spring (Figure 20). This model brought another significant advance in design, which was crossing the springs at the hub.

'I evolved the design to think: if I cross the springs I get a really nice torsional action.

So, that's what's happened.' 


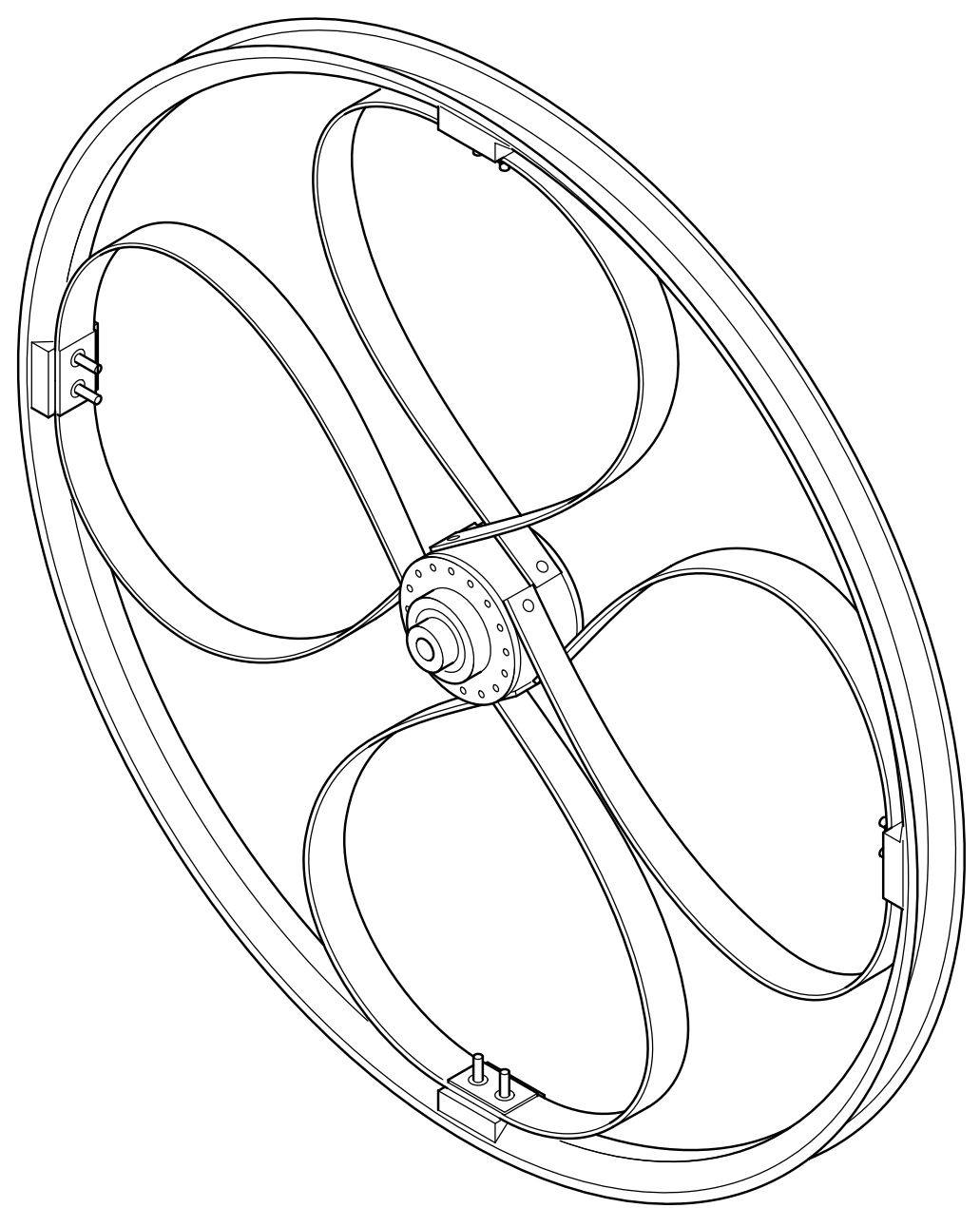

Figure 20. Sam's revised 26-inch prototype wheel, with four springs meeting tangentially at the rim and crossing at the hub.

This prototype was a real leap for Sam, with the springs now meeting the hub and the rim tangentially rather than obliquely. From that moment onwards he started thinking that his wheel design had real potential to become a commercial product. He proceeded to conduct a patent search to identify any relevant prior art, identifying over twenty relevant patents, mostly from the early 1900s. A number of these explored radial suspension in various configurations but there were no materials available at that time which would have allowed for the construction of an effective suspended wheel.

'The reason why in-wheel suspension [isn't] here now is because the materials weren't good enough. So, it's purely a technology path really. That's what we're finding, that quite a lot of our work is down to the materials not quite there yet, for really specific applications.' 
Sam addressed the problem of material selection by developing new materials for the springs in conjunction with developing new wheel designs. In particular, he tested hundreds of carbon composite recipes to improve the performance of the springs.

'But the actual recipes we did with [the carbon specialist], we'd literally do a recipe every day and make one and test it. But at this point [...] we're nowhere near a product.'

By studying the patents, together with learning from his own prototypes, Sam realised that making radial suspension work was a mechanics problem that required consideration of radial compliance, lateral stiffness and torsional stiffness.

'So, we've got three things going on: compression, lateral and torsional. If I can get all of those correct, then l've got a product.'

A few months later, Sam decided to change wheel size again, and made a prototype for a 20 " wheel, thinking that it would be easier to resolve the competing technical requirements on a smaller wheel. It was also a market-driven decision, as he thought that a radial suspension wheel could be useful in a folding commuter bike that would otherwise be too small to house other forms of suspension.

'Technically I was getting nowhere with the big wheel, [for] the lateral loading I just wasn't getting the results I needed. Someone said, put it on a Brompton-style [folding] bike, you've got smaller diameters so, your lateral loading is easier to achieve and there's a market for suspension [on those bikes]. Obviously, it's a little bike, little commuter bikes [where] you can't do it with forks or suspension in other ways. Well, you can, but it's expensive. This is where we started to formulate a bit of a commercial plan as well.'

At the time, Sam was intending to develop and protect the intellectual property for the suspended wheels and then sell or license the design to a company operating in that market (e.g. bicycles or bicycle components). However, to develop the concept further, more work was necessary and reducing costs (both development costs and product costs) was important. One way to lower the development costs was to reduce the number of springs used in the prototype, a move that would subsequently reduce product costs, but also happened to improve performance.

'I realised it was getting expensive, so the inventive step, the leap, was actually based on three springs in here and not four. [...] I realised that having four springs or 
loops was actually making it less efficient. Because the springs opposite each other were fighting each other. Basically, the identical set up of wheel with four springs was less efficient and less laterally stiff than three springs. So, that was a big breakthrough.'

Here, different kinds of requirements interacted, with cost reduction and performance improvements being tightly connected. Sam initially explored the three-loop wheel because of a concern for reducing the cost, and then realised that the new design was also more efficient.

'That happens a lot actually. It happens a lot where you have a [...] commercial [driver] and suddenly it forces you into rethinking how you're doing it and it has beneficial results [technically].'

To continue improving the performance of the three-loop wheel, Sam started looking at what happened to the springs during compression and realised that bending each long spring into a loop shape in the wheel was resulting in a preloading effect that reduced efficiency. This caused him to move to a design in which each of the three loops was composed of two smaller half-loops that could be joined together to create a single-loop spring that required no preloading (see Figure 21). 


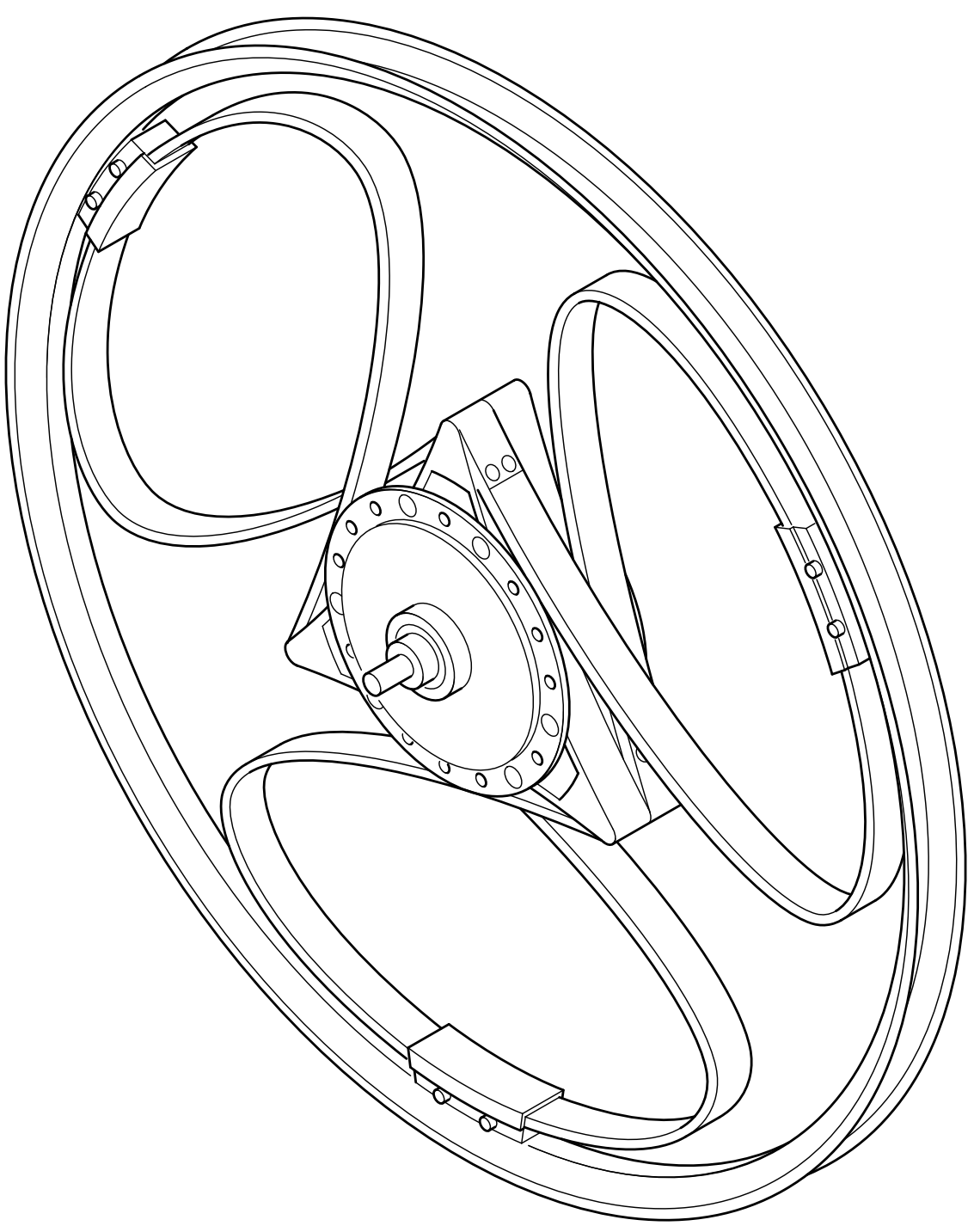

Figure 21. Sam's 20-inch suspended wheel with three springs, each comprised of two parts, connected tangentially at the rim. The springs are only lightly stressed when inserted into the frame.

'The preloading reduces efficiency, and we need as much efficiency as we can. So actually, we decide at this point... So, this shape is the most efficient shape. [...] Compared with the cost of everything else, about $60 \%$ of the wheel cost is in the spring. Because of the carbon and what it's doing, it's having to work very hard. You can't compromise on that.'

In April 2013 Sam launched the first production-ready wheel on Kickstarter to raise money for manufacturing. This was a 20 -inch wheel with three loops, each made of two carboncomposite springs which crossed at the hub. With this design, he was then able to build a viable working model of a folding bike with radial suspension which he exhibited at the 2013 UK Handmade Bicycle Show. 
For Sam this marked a new point in the Loopwheel journey as a viable design for the wheel had now been reached. Meanwhile, a wheelchair user persuaded Sam to develop 24-inch suspended wheel for wheelchairs, to increase user comfort and reduce fatigue. Sam then started working on these larger wheels and also 26 -inch wheels for mountain bikes.

'At the same time as we did the wheelchair wheel we said, okay, let's look at doing the mountain bike wheel again. So, [taking] the same geometry and moving it forward and then actually, using more computational software to figure out how we could get that leap to increase the lateral stiffness. No more iteration back and forth, let's put some computer work behind it to see how we can make this next evolutionary step to get to bigger bike wheels.'

In addition to using computational design tools, it was useful for Sam to be able to work with standard CAD tools, as he was constantly moving between different wheel sizes and thus component sizes.

'So, the CAD is really important because l'm able to control the 30 components, the iterations, the 20 or 30 different designs l've had, all on the CAD. Now what I do, if I'm doing a new design, l'll literally nick the spring design for that wheelchair wheel, chuck it into my CAD, slash it up, chuck in a hub from wherever, mix and match it all and I can then quickly make a prototype. I'm not worried, it's kind of like a virtual toolbox of bits I can fling in there. It's about 3D printing, make one, try it, if that's no good, dump it. So, actually the CAD is really important to the flexibility of development.'

With the flexibility offered by the CAD workflow, Sam soon had functional prototypes for the larger wheels. Each of the three products required a different balance of performance characteristics and the lessons learnt from working on one product were often transferred to the others. However, although the initial plan was not to manufacture the wheels directly, but to sell or license the design, there was market resistance to this approach. This led Sam to establish a manufacturing operation to build and sell the wheels directly. The 24 -inch wheelchair wheel is currently Loopwheels' leading product, which is manufactured in Nottinghamshire and sold globally.

\section{Thematic analysis}

The three narratives presented above offer chronological descriptions of the design projects, documenting the development of new ideas through the accounts of the designers and through the representations of the prototypes constructed. Further analysis of the interview 
transcripts identified several recurring themes that connect to the prevailing discourse on design creativity and fixation. For example, the projects share many features with the studies reviewed by Crilly (in press), especially with respect to the self-motivated nature of the work, the persistence demonstrated by the designers and the importance of making and testing in product development. However, we here focus on themes that are more central to the questions with which this article began, themes related to the development of design ideas and themes with which much of the design creativity literature engages. For convenience, we arrange this discussion under three distinct headings, whilst recognising that the themes overlap: (1) blocks and breakthroughs; (2) evolution and co-evolution; (3) recognition and acceptance. For each of these themes, we identify the relevant features of the three cases, connect and contrast them to each other and also to prior work.

\subsection{Blocks and breakthroughs}

The three cases described here all involved challenging prevailing assumptions about how a certain product should be, but also challenging the designers' own representations of the possible problems and possible solutions. As such, the cases depict fixation and creative breakthroughs in different ways. In categorising fixation, Youmans and Arciszewski (2014) propose distinctions between unconscious adherence, conscious blocks and intentional resistance. So, what varieties of fixation do we see in the cases reported here? Brian's initial focus on the shape of the holes appears to be a case of unconscious adherence, until his attention was redirected to considering the remaining material as a structure; Min-Kyu's persistence with the original sequence of operation might have looked like unconscious adherence but his own account reveals that it was intentional resistance; Sam's original sketch indicated three springs but he neither adhered to this idea nor resisted its return (he moved to a four-spring and then later a three-loop design). With respect to Crilly's (2015) distinctions between problem-, solution- and process-fixation, Brian's example might be seen as relating to all of them, depending on whether attention is focussed on the problem of lightening a plate, the solution of implementing lightening holes or the process of increasing hole area. As these examples show, fixation typologies are useful not just for characterising different types of fixation, but also different perspectives on any given fixation episode.

If fixation-related phenomena can be identified in real-world cases, is this also possible for the so-called 'creative leap'? Referring back to our three cases, Brian's recognition of the potential for the triangulated truss structure is certainly described as sudden, but also as inevitable once the problem of material efficiency emerges and repeated geometry becomes a feature of the design; Min-Kyu's shift in focus from the power plug to the adapter is more gradual and is driven by market forces; Sam's development of the loop geometry is more 
complex and iterative, solving different problems for different applications and then combining them. Rather than viewing any of these episodes as a creative 'leap', Cross's (1997a; 1997b) model of a creative 'bridge' might be more appropriate. All three designers were involved in making a series of design moves that brought the problem and the solution closer together (also see Yilmaz \& Seifert, 2011). However, any new insight that the designers had which subsequently led to a change in design direction - no matter how productive that might subsequently prove to be - was soon followed by a new set of problems that were specific to that new direction. It seems that even if creative breakthroughs occur they might in any case take the designer directly to new chasms that must then be crossed (whether by leaping or bridging).

The idea of leaping or bridging to new chasms is reminiscent of Takala's (2005) depiction of a cyclic pattern of problem identification, strategy formulation, fixation, frustration, reformulation, refixation, and so on. This description was based on the behaviour of software agents, but we see a similar pattern in our cases here. However, in our cases there is the added issue of how a person's confidence in a breakthrough (or new strategy) is diminished by the impasses it subsequently leads to. This is especially relevant where such impasses are not a feature of the preceding direction but are entirely new challenges that are only relevant because of some change in direction. Brian's fastening challenges (tabs, slots and welds), Min-Kyu's usability challenges (pins first or wings first) and Sam's various compliance challenges were all issues that only needed to be addressed because of earlier breakthroughs (imagining a saw frame as a multi-part structure, a plug that changes shape, and a wheel as a suspension system). Therefore, considering these various breakthrough ideas in isolation, and representing them as the essence of the creative project would be misleading. Here it was often the challenges that resulted from the breakthroughs that were more interesting because those challenges were, on the one hand, associated with the preceding original idea ("I'm onto something!"), and yet that idea is also the source of the current challenge ("I can't get this to work"). Getting stuck and getting unstuck might be a continual process, played out repeatedly in different parts of a project, whether focussing on overall concepts or small details. A process of this kind is visible in the accounts of technological development projects which played out over long time periods (e.g. Anderson \& Tushman, 1990; Constant, 1980; Dosi, 1982; Vincenti, 1990) but not with respect to design projects. We might develop very different theories of blocks and breakthroughs if they are studied in connection not only to established ideas but also to new and exciting ones that originate with the designer. 


\subsection{Co-evolution and ecologies}

In our three cases, the creative development of the projects permitted flexibility in defining not just the object being designed but also the application for that object (such as satisfying a particular need). Such interactions are common where designers or entrepreneurs have an evolving understanding of their new technology and also an evolving understanding of the markets that the technology relates to (Crilly, 2018; Grimes, 2017). This is connected to discussions about the co-evolution of problem- and solution-spaces. For example. Fischer and Nakakoji (1991) describe design as the "coevolution of problem setting and problem solving" (p. 67), a process which they represent as a parallel and iterative interaction between those two activities, resulting in a single problem-solution match (Fischer \& Nakakoji: 1992: pp. 18, 22; also see Yeh, 1991). Similar perspectives on design have been formalized (e.g. Maher, 1994; Maher, 2000, Maher \& Poon, 1996) and used to frame the analysis of design practice (e.g. Dorst \& Cross, 2001; Maher \& Tang, 2003; Wiltschnig et al., 2013). These co-evolution accounts all allow for a clear and enduring distinction between two design spaces: 'problems' and 'solutions' (also see Daly, McKilligan, Studer, Murray \& Seifert, 2018). Although it might be possible to make a similar distinction in the cases described here, it is a closer fit to the data if we instead talk more generally of multiple design spaces being navigated, each at multiple levels.

Let's consider some of the spaces that our designers are exploring: Brian explores options for shape tessellation, structural configurations and joining methods; Min-Kyu explores transformation options, product categories and business models; Sam explores business models, application vehicles and product architecture. Many of these explorations are conducted at various levels, examining detailed issues (e.g. which order of folding) 'within' broader issues (e.g. whether to fold or twist). Examining Sam's example further, we can see that with the basic suspended wheel concept in place, finding the wheelchair application is either an instance of finding a solution for the problem (the problem of identifying an application vehicle) or an instance of finding a problem for the solution (the solution of the suspended wheel). The distinction is arbitrary, but in any case there is also the need for Sam to find an appropriate business model (e.g. licencing the intellectual property or becoming a manufacturer), find the best architecture (e.g. how many springs, how configured and how attached at the hub and rim), and so on. Those spaces could also arbitrarily be framed as relating to problems or solutions, or sub- or super- variants of other problems or solutions. More generally, in developing their designs beyond an initial ideation stage, our designers collectively considered how the designed objects would be used, configured, developed, tested, made, distributed, sold and serviced, amongst other things. So, they were not necessarily only working towards a good match between a single part of a single problem- 
space and a single part of a single solution-space. Instead they were working towards a good match between multiple parts of multiple spaces, each with multiple levels of detail.

In biological science, co-evolution describes the reciprocal effect that two or more species have on each other's evolutionary path (e.g. see Hembry, Yoder, Goodman, Bolnick, \& Kalisz, 2014: p. 425). Although in biology and elsewhere, co-evolution is often discussed in terms of only a pair of co-evolving species (e.g. predator-prey, host-parasite) this restriction is not necessary and the co-evolution of multiple species within an ecology is also considered (e.g. see Urban et al., 2008), as is the co-evolution of a species' multiple capabilities (e.g. see Pinker, 2010). Looking at fields close to design we can find discussions of how technological ecologies develop with respect to more than two co-evolving systems and where one system might exist within the other. For example, is consideration of the coevolution of knowledge, capabilities and products at the organizational level (Helfat \& Raubitschek, 2000), the co-evolution of products, processes and production at the industry level (Tolio et al., 2010) and co-evolution firms, technology and institutions at the national level (Murmann, 2003). Similarly, reflecting on the design activities described in our cases suggests that the standard models of design co-evolution might be usefully modified to represent the interrelated development of an ecology of design spaces including multiple sub-spaces and super-spaces.

\subsection{Recognition and acceptance}

Although all three of the cases reported here involve the development of new ideas, the accounts do not place a strong emphasis on divergent ideation. Only Min-Kyu describes a specific divergent thinking phase when he examines the various possible ways to reconfigure the parts that make up the plug. Brian and Sam try out different ideas for their products but they are seemingly not working through a wide range of options prior to building and testing prototypes. Similarly, in the prior case studies reviewed by Crilly (in press), only the account of Sanders' project documents a specific divergent thinking phase (Roy, 1993: p. 433; but also see Yilmaz \& Seifert, 2011; Dogan \& Nersessian, 2010). Even then, Min Kyu's creativity seems most apparent in his initial questioning of the 'static' nature of the original plug design and in his subsequent refinement of the folding option (an option that he committed to quite quickly). For Brian and Sam too, it is not some wide-ranging exploration of ideas that is most apparent, but identifying the value in an idea, playing with it, committing to it, making it work and refining it further. Although divergent thinking gets a lot of attention in design creativity research, convergent thinking and depth of exploration are also recognised as important aspects of creative design (e.g. see Cropley, 2006; Kazakci, Gillier, Piat \& Hatchuel, 2015; McComb, Cagan, \& Kotovsky, 2015). In the cases reported here, 
these are the aspects of creativity that drive the development of something useful into something that is also novel (Brian) or something novel into something that is also useful (Min-Kyu and Sam). Either way, that development requires new ideas not just to be generated, but to be recognised and accepted.

Although all three of the products ultimately represented a step change in terms of how products in that category are normally considered, the idea for that change arose differently in each case. For Brian, there is no guiding idea for a 3D truss at the outset, but through continual development one material is replaced by another, a single part is broken into multiple parts, a lightened plate is replaced by a truss, and a 2D frame is converted into a 3D frame. The recognition and acceptance of ideas is required at each stage. In contrast, for Min-Kyu and Sam, there are clear ideas at the outset (a folding plug, a suspended wheel) and those ideas are recognised, accepted and pursued to completion. Even then, within those ideas there are variants to be explored and applications to be identified, which in themselves must be recognised and accepted. Processes that look like unconstrained invention from the outside can be seen as laborious discovery when examined more closely, and within those acts of discovery there are acts of invention (see Crilly, 2010; Suwa, Gero, \& Purcell, 2000). So, whether the processes involved in the three cases look fundamentally the same or different is seemingly just a matter of perspective. There are aspects of invention and discovery in all of them as ideas are generated, recognised, accepted or rejected.

Two of the accounts presented here place more emphasis on the process of accepting an idea than the process of generating it. Brian seemingly immediately understands the potential for welding the titanium parts together (he might be expected to, given his background), but it is only much later that he finally accepts that he should test this idea. At that moment, the breakthrough is not the idea itself, but overcoming his well-founded resistance to it and then recognizing just how well it might work. Similarly, Min-Kyu eventually accepts the wings-then-pins design which he had long ago identified even if he did not initially recognize all its benefits. Sam's case does not offer such an account of idea acceptance and recognition, but Hickman's does (Hickman \& Roos, 1982; Landis, 1998): after much resistance, he finally accepts the bench-top-as-vice concept that he had considered much earlier, recognizing that the benefits outweighed the perceived shortcomings (for a summary, see Crilly, in press). As with Hickman's account, in our cases, Brian and Min-Kyu both refer to how strange their ideas appeared at first and how they consequently pursued design directions that made those ideas appear more normal (narrowing the 3D structure, presenting a flat surface to the socket). With respect to this, prior research has focussed on how people recognise and assess other people's creative 
ideas (Mueller, Melwani \& Goncalo, 2012; Mueller, Wakslak \& Krishnan, 2014) and how they select between creative ideas originating from themselves or others (Kornish \& HutchisonKrupat, 2017; Rietzschel, Nijstad \& Stroebe, 2010). However, our cases present idea recognition and acceptance as part of the creative process itself. If we consider the acceptance of a novel product, clearly some anticipated future market must accept the product and might be a concern for the designer. However, so too must the designer accept the idea and it is the designer who ultimately constitutes the first 'market' that such an idea must satisfy. Without recognising the value in an idea and accepting it, the development of those ideas might not be possible or productive.

\section{Limitations and future work}

The three projects described here were all undertaken by designers working largely alone or sometimes with one or two other people (at certain phases of the project). We might be interested in studying the practices of designers working primarily in isolation for at least two different reasons: first, many designers work that way and such work makes up part of the innovation landscape (Freeman \& Engel, 2007; Meyer, 2005; but also see Singh \& Fleming, 2010); second, even when working as part of a team, designers may work independently for much of the time (see empirical work by Ancona \& Caldwell, 1990) and combining group work with lone work offers some creative advantages (e.g. see Kohn \& Smith, 2011; Mullen, Johnson, \& Salas, 1991). However, there are also many design contexts in which group work is a key element and where responsibility for idea production and idea development is effectively shared (e.g. see Kohn \& Smith, 2011; Martinec, Škec, Horvat, \& Štorga, 2019). This is not addressed in the accounts we offer here and also not emphasised in many of the case studies conducted previously (but see Dogan \& Nersessian, 2010; Cross, 2001).

Studying real-world cases of group design creativity would add a valuable component to our descriptions of how design ideas are developed in different contexts. Such studies might collect data in the way reported here, but obtaining multiple accounts for each project would potentially reveal and compensate for various forms of respondent bias and allow comparison of perspectives across different participants (for a discussion in the context of new product development, see Ernst \& Teichert, 1998). Alternatively, or additionally, the data could be collected at regular team meetings, where different members are naturally required to share their perspectives on the project without intervention from the researcher (e.g. for such a study of creativity in science, see Dunbar, 1997; for design see Christensen \& Schunn, 2007; Wiltschnig, Christensen, \& Ball, 2013). 
In addition to their individual work, the three projects reported here are also particular in other ways that future studies might usefully react against. For example, none of the projects were conducted within large organisations that have an established process for supporting or encouraging creativity and innovation (again, the same is true for most of the prior case studies). Very different project accounts might be collected from corporate research and development units or design and innovation consultancies where new product development is a routine activity (e.g. see Kalogerakis, Lüthje, \& Herstatt, 2010). As dictated by our sampling strategy, the products were mostly mechanical or structural in nature (or at least those are the aspects that are emphasised here), but distinct development issues might be identified when the design challenges relate to, for example, electronics, software, architecture or infrastructure. The cost of realistic models varies enormously between different design disciplines and therefore the role of simulation and prototyping in the creative process might be expected to vary too (for a discussion of the economics of switching between simulation and prototyping, see Thomke, 1998). Taking this further, where services, experiences or processes are being designed, constructing useful representations and testing those might radically change the nature of the creative work (e.g. see Potts et al., 2008).

The report on each project relied on the participant's own account of the design process. This involved recall and introspection and might thus be subject to various biases, including hindsight bias and self-presentation bias (Perkins, 1981, pp. 13-32; Podsakoff, 1986; for a discussion of such problems in design accounts, see Cross, 2018: p. 374). However, the extensive reference to sketches and prototypes in the interviews tied the discussions down to those aspects of the process for which there was some evidence (for a similar argument see Candy \& Edmonds, 1996: p. 74), and the resulting accounts neither present the final product as inevitable nor the designers as infallible. Still, one caution on conducting research using these design materials is that the record they provide will always be incomplete, as some of these design materials are either lost or reworked into new materials (e.g. 'cannibalising' one prototype to make another). In our study, all of the participants had many physical models and prototypes available to share and had visual records of more. Future studies could aim to combine the collection of real-time data with retrospective data to ensure a more complete design record is maintained. The benefits of such a move would then have to be balanced with any associated problems of the research affecting the process under investigation and difficulties negotiating regular access to live projects. 


\section{Conclusions}

Creative design is central to innovation and is thus highly valued in industry and society. Developing a better understanding of design creativity is necessary, both to improve design education and to provide better support to practising designers. In this paper we have sought to contribute to that understanding by adding to the relatively small number case studies documenting real world creative design projects. In particular, our cases are distinct from those that precede them in focussing on three particular aspects: (1) the development of design ideas through the project rather than just the breakthrough that either characterised the initial concept or the final outcome; (2) the sequence of physical models and prototypes that were used to develop design ideas; (3) the personal accounts of the designers in explaining the reasons that changes were made when they were. Although previous cases have one or more of those features, they rarely or never have all three. Perhaps Hickman's account is closest, but it is not a research account and certain details of the project might have been investigated more closely if creativity and fixation (or other design research issues) were being considered explicitly.

Having in-depth accounts of real-world design projects emphasises a number of themes that do not necessarily arise from the application of other research methods. For example, our accounts add support to the themes identified in some previous case studies, themes related to problem identification, personal tenacity and ideation through making. However, they also connect with themes that have been studied by other methods, including fixation, co-evolution and idea selection. When those themes are considered in the context of our real-world case studies, a number of new observations arise. First, fixation and defixation can be productively considered not just as momentary events, but as ongoing processes where, for example, the idea being fixated on might have been a previous breakthrough. Defixating from something that has previously seemed productive might be a very different process - and might require different forms of support - to defixating from the effects of a more neutral stimulus. Second, co-evolution applies to more than just a pair of problem- and solution-spaces; the distinction between problems and solutions might not be so clear anyway and each has more general and more detailed aspects. Instead, a design project might be seen to progress through the co-evolution of design spaces that make up a more complex ecology. Third, it need not be the generation of new ideas that provides a breakthrough, but the recognition of such ideas and the way in which their value is accepted. This is because new ideas are likely to appear strange and uncomfortable, not just to others, but to the designer as well. 
The observations summarised above connect with the suggestion that Gruber makes in the opening quotation: the development of new, useful and surprising things is not necessarily characterised by a single breakthrough but by an ongoing process that connects many interacting moves. Collectively, the cases presented here, both in narrative and thematic form illustrate this by emphasising the complex, iterative and persistent nature of creative work. In doing so, they provide new avenues of enquiry that can be followed in future research, but also provide a basis for reinterpreting research that has already been conducted.

\section{Acknowledgements}

The authors are extremely grateful to Brian, Min-Kyu and Sam for agreeing to participate in the study and for being so generous with their time and other resources over an extended period. We are also grateful for the very helpful comments from the editors and reviewers involved in with this submission. The technical illustrations were produced by Rob Woods based on the original case study materials collected by the researchers. Permission to reproduce extracts from BS 1363-1:2016 is granted by BSI. British Standards can be obtained in PDF or hard copy formats from the BSI online shop: www.bsigroup.com/Shop or by contacting BSI Customer Services for hardcopies only: Tel: +44 (0)20 8996 9001, Email: cservices@bsigroup.com. This work was supported by the UK's Engineering and Physical Sciences Research Council (grant number EP/K008196/1). The raw interview data from this study cannot be made freely available because inherent to that data is sensitive information relating to the individuals and organizations involved.

\section{References}

Ancona, D. G., \& Caldwell, D. (1990). Improving the Performance of New Product Teams. Research-Technology Management, 33(2), 25-29.

Anderson, P., \& Tushman, M. L. (1990). Technological discontinuities and dominant designs: a cyclical model of technological change. Administrative Science Quarterly, 35(4), 604-633.

Candy, L., \& Edmonds, E. (1996). Creative design of the Lotus bicycle: implications for knowledge support systems research. Design Studies, 17(1), 71-90.

Christensen, B. T., \& Schunn, C. D. (2007). The relationship of analogical distance to analogical function and preinventive structure: The case of engineering design. Memory \& Cognition, 35(1), 29-38. 
Constant, E. W. (1980). The origins of the turbojet revolution. Baltimore, MD: Johns Hopkins University Press.

Crilly, N. (in press). Creativity and fixation in the real world: a literature review of case study research. Design Studies.

Crilly, N. (2010). The Structure of Design Revolutions: Kuhnian Paradigm Shifts in Creative Problem Solving. Design Issues, 26(1), 54-66.

Crilly, N. (2015). Fixation and creativity in concept development: The attitudes and practices of expert designers. Design Studies, 38, 54-91.

Crilly, N. (2018). 'Fixation' and 'the pivot': balancing persistence with flexibility in design and entrepreneurship. International Journal of Design Creativity and Innovation, 6(1-2), 52-65.

Crilly, N., \& Cardoso, C. (2017). Where next for research on fixation, inspiration and creativity in design? Design Studies, 50, 1-38.

Cropley, A. (2006). In Praise of Convergent Thinking. Creativity Research Journal, 18(3), 391-404.

Cross, N. (1997a). Descriptive models of creative design: application to an example. Design Studies, 18(4), 427-440.

Cross, N. (1997b). Creativity in Design: Analyzing and Modeling the Creative Leap. Leonardo, 30(4), 311-317.

Cross, N. (2001). Achieving Pleasure from Purpose: the Methods of Kenneth Grange, Product Designer. The Design Journal, 4(1), 48-58.

Cross, N. (2018). 'Expertise in Professional Design', in The Cambridge Handbook of Expertise and Expert Performance, K. A. Ericsson, N. Charness, P. J. Feltovich, \& R. R. Hoffman (Eds.) pp. 372-388. Cambridge, UK: Cambridge University Press.

Daly, S. R., McKilligan, S., Studer, J. A., Murray, J. K., \& Seifert, C. M. (2018). Innovative Solutions through Innovated Problems. International Journal of Engineering Education, 34(2(B)), 695-707.

Dogan, F., \& Nersessian, N. J. (2010). Generic abstraction in design creativity: the case of Staatsgalerie by James Stirling. Design Studies, 31(3), 207-236.

Dorst, K., \& Cross, N. (2001). Creativity in the design process: co-evolution of problemsolution. Design Studies, 22(5), 425-437.

Dosi, G. (1982). Technological paradigms and technological trajectories: a suggested interpretation of the determinants and directions of technical change. Research Policy, 11(3), 147-162.

Dunbar, K. (1997). How scientists think: On-line creativity and conceptual change in science. In T. B. Ward, S. M. Smith, \& J. Vaid (Eds.), Creative thought: An investigation of conceptual structures and processes (pp. 461-493). Washington, DC: American Psychological Association. 
Eisenhardt, K. M. (1989). Building Theories from Case Study Research. The Academy of Management Review, 14(4), 532.

Ernst, H., \& Teichert, T. (1998). The R and D/Marketing interface and single informant bias in NPD research: an illustration of a benchmarking case study. Technovation, 18(12), 721739.

Fielding, J. (2001). Coding and Managing Data. In Researching Social Life (pp. 227-251). London, UK: SAGE Publications.

Fischer, G., \& Nakakoji, K. (1991). Making Design Objects Relevant to the Task at Hand. AAAl-91 Proceedings, 67-73.

Fischer, G., \& Nakakoji, K. (1992). Beyond the macho approach of artificial intelligence: empower human designers - do not replace them. Knowledge-Based Systems, 5(1), 1530.

Flyvbjerg, B. (2006). Five Misunderstandings About Case-Study Research. Qualitative Inquiry, 12(2), 219-245.

Freeman, J., \& Engel, J. S. (2007). Models of Innovation: Startups and Mature Corporations. California Management Review, 50(1), 94-119.

Grimes, M. G. (2017). The Pivot: How Founders Respond to Feedback through Idea and Identity Work. Academy of Management Journal, 61(5), 1692-1717.

Gruber, H. E. (1980) Afterword, in D. H. Feldman (ed) Beyond universals in cognitive development, Norwood, NJ: Ablex Publishing Corp. pp 177-178.

Helfat, C. E., \& Raubitschek, R. S. (2000). Product sequencing: co-evolution of knowledge, capabilities and products. Strategic Management Journal, 21(10-11), 961-979.

Hembry, D. H., Yoder, J. B., Goodman, K. R., Bolnick, A. E. D. I., \& Kalisz, E. S. (2014). Coevolution and the Diversification of Life. The American Naturalist, 184(4), 425-438.

Hickman, R. P. \& Roos, M. J. (1982) 'Workmate', CIPA Journal, July: 424-457. London, UK: Chartered Institute of Patent Attorneys.

Jewkes, J., Sawers, D., \& Stillerman, R. (1958). The sources of invention. London, UK: Macmillan.

Kalogerakis, K., Lüthje, C., \& Herstatt, C. (2010). Developing Innovations Based on Analogies: Experience from Design and Engineering Consultants. Journal of Product Innovation Management, 27(3), 418-436.

Kazakci, A. O., Gillier, T., Piat, G., \& Hatchuel, A. (2015). Brainstorming vs. Creative Design Reasoning: A Theory-Driven Experimental Investigation of Novelty, Feasibility and Value of Ideas. In J. S. Gero \& S. Hanna (Eds.), Design Computing and Cognition '14 (pp. 173-188). Heidelberg, Germany: Springer International Publishing.

Knew Concepts (2017). "Knew Concepts Titanium Birdcage Fret Saws," http://www.knewconcepts.com/titaniumSaws.php, accessed on 4 December 2017. 
Kohn, N. W., \& Smith, S. M. (2011). Collaborative fixation: Effects of others' ideas on brainstorming. Applied Cognitive Psychology, 25(3), 359-371.

Kornish, L. J., \& Hutchison-Krupat, J. (2017). Research on Idea Generation and Selection: Implications for Management of Technology. Production and Operations Management, 26(4), 633-651.

Landis, S. (1998). The Workbench Book: A Craftsman's Guide to Workbenches for Every Type of Woodworking. New Town, CT: The Taunton Press, Inc.

Loopwheels (2017) "Reinventing the wheel for a smoother ride," https://www.loopwheels.com, accessed on 4 December 2017.

Maher, M. L. (1994). Creative design using a genetic algorithm. Computing in Civil Engineering, 2, 2014-2021.

Maher, M. L. (2000). A model of co-evolutionary design. Engineering with Computers, 16, 195-208.

Maher, M. L., \& Poon, J. (1996). Modeling design exploration as co-evolution. Microcomputers in Civil Engineering, 11(3), 195-209.

Maher, M., \& Tang, H.-H. (2003). Co-evolution as a computational and cognitive model of design. Research in Engineering Design, 14(1), 47-64.

Martinec, T., Škec, S., Horvat, N., \& Štorga, M. (2019). A state-transition model of team conceptual design activity. Research in Engineering Design, 30(1), 103-132.

McComb, C., Cagan, J., \& Kotovsky, K. (2015). Rolling with the punches: An examination of team performance in a design task subject to drastic changes. Design Studies, 36, 99-121.

Meyer, M. (2005). Independent inventors and public support measures: insights from 33 case studies in Finland. World Patent Information, 27(2), 113-123.

Mueller, J. S., Melwani, S., \& Goncalo, J. A. (2012). The Bias Against Creativity: Why People Desire but Reject Creative Ideas. Psychological Science, 23(1), 13-17. https://doi.org/10.1177/0956797611421018

Mueller, J. S., Wakslak, C. J., \& Krishnan, V. (2014). Construing creativity: The how and why of recognizing creative ideas. Journal of Experimental Social Psychology, 51, 81-87. https://doi.org/10.1016/j.jesp.2013.11.007

Mullen, B., Johnson, C., \& Salas, E. (1991). Productivity Loss in Brainstorming Groups: A Meta-Analytic Integration. Basic and Applied Social Psychology, 12(1), 3-23.

Murmann, J. P. (2003). Knowledge and Competitive Advantage: The Coevolution of Firms, Technology, and National Institutions. Cambridge, UK: Cambridge University Press.

Peacock, D. (2013). The remarkable evolution of BS 1363 (Wiring Feature \#49). IET Wiring Matters, Winter, 18-21.

Perkins, D. N. (1981). The mind's best work. Cambridge, MA: Harvard University Press. 
Pinker, S. (2010). The cognitive niche: Coevolution of intelligence, sociality, and language. Proceedings of the National Academy of Sciences, 107(Supplement 2), 8993-8999.

Polkinghorne, D. E. (1995). Narrative configuration in qualitative analysis. International Journal of Qualitative Studies in Education, 8(1), 5-23.

Podsakoff, P. M. (1986). Self-reports in organizational research: problems and prospects. Journal of Management, 12(4), 531-544.

Potts, J., Hartley, J., Banks, J., Burgess, J., Cobcroft, R., Cunningham, S., \& Montgomery, L. (2008). Consumer Co-creation and Situated Creativity. Industry and Innovation, 15(5), 459474.

Rietzschel, E. F., Nijstad, B. A., \& Stroebe, W. (2010). The selection of creative ideas after individual idea generation: Choosing between creativity and impact. British Journal of Psychology, 101(1), 47-68. https://doi.org/10.1348/000712609X414204

Roy, R. (1993). Case studies of creativity in innovative product development. Design Studies, 14(4), 423-443.

Royal College of Art (n.d.). "Min-Kyu Choi". https://www.rca.ac.uk/students/min-kyu-choi/, accessed on 8 October 2018.

Singh, J., \& Fleming, L. (2010). Lone Inventors as Sources of Breakthroughs: Myth or Reality? Management Science, 56(1), 41-56.

Stake, R. E. (1995). The Art of Case Study Research. Thousand Oaks, CA: Sage Publications Inc.

Suwa, M., Gero, J., \& Purcell, T. (2000). Unexpected discoveries and S-invention of design requirements: important vehicles for a design process. Design Studies, 21(6), 539-567.

Takala, T. (2005). Creativity as disruptive adaptation - A computational case study. In J. S. Gero \& M. L. Maher (Eds.), Computational and Cognitive Models of Creative Design VI (pp. 95-110). University of Sydney, Australia.

The Mu (2017). "The world's thinnest USB charger range," https://www.themu.co.uk, accessed on 4 December 2017.

Thomas, D. R. (2006). A General Inductive Approach for Analyzing Qualitative Evaluation Data. American Journal of Evaluation, 27(2), 237-246.

Thomke, S. H. (1998). Managing Experimentation in the Design of New Products. Management Science, 44(6): 743-762.

Tolio, T., Ceglarek, D., EIMaraghy, H. A., Fischer, A., Hu, S. J., Laperrière, L., ... Váncza, J. (2010). SPECIES-Co-evolution of products, processes and production systems. CIRP Annals, 59(2), 672-693.

Urban, M., Leibold, M., Amarasekare, P., Demeester, L., Gomulkiewicz, R., Hochberg, M., ... Norberg, J. (2008). The evolutionary ecology of metacommunities. Trends in Ecology \& Evolution, 23(6), 311-317.

Wiltschnig, S., Christensen, B. T., \& Ball, L. J. (2013). Collaborative problem-solution coevolution in creative design. Design Studies, 34(5), 515-542. 
Yeh, R. T. (1991). System development as a wicked problem. International Journal of Software Engineering and Knowledge Engineering, 01(02), 117-130.

Yilmaz, S., \& Seifert, C. M. (2011). Creativity through design heuristics: A case study of expert product design. Design Studies, 32(4), 384-415.

Yin, R. (1984). Case study research: design and methods. London, UK: SAGE Publications.

Youmans, R. J., \& Arciszewski, T. (2014). Design fixation: Classifications and modern methods of prevention. Al EDAM, 28(02), 129-137. 


\section{Appendix}

\section{Thematic coding scheme}

1. Acceptance

2. Change

3. Co-evolution

4. Constraints

5. Core idea

6. Creativity

7. Depth/Breadth

8. Discovery

9. Fixation

10. Learning a. ... that an idea will be pursued

b. ... that an idea will be abandoned
a. ... in the information available
b. ... in the perspective adopted
c. ... in the conditions of operation
d. ... of idea changes the whole project
a. (related to application areas)
b. (related to business model)
c. (related to production process)
d. ... of problems and solutions
e. ... of details and overall concept
a. ....act as a stimulus to creativity
b. ... on project
c. ... on product
a. , the generation of the
b. , the development of the
c. ... is something that drives the project
d. ... is present at the outset and then pursued
e. ... is developed through the process
a. ... throughout the process
b. ... in refining the details
c. .... in changing the application
d. ... in recognising the value of ideas
e. ... in persistence
f. ... in developing ideas, not generating them
a. Deep exploration of a single option
b. Deep exploration of multiple options
c. Broad exploration of multiple options
a. ... that a previous idea is valuable
b. ... of how well something works
c. ... that something doesn't work
a. ... as the unconscious repetition of ideas
b. , the external appearance of
c. , the awareness of
d. ... on prior solutions (or not)
a. ... more about the problem
b. ... more about the market
c. ... more about the prior art 
11. Manufacture

a. Anticipating manufacture early in process

b. Continuity with prototyping

12. Motivation
a. ... is derived from personal need
b. .... is derived from connection to users
c. ... is intrinsic

13. Other people
a. ... provide new information
b. ... provide new perspectives
c. ... provide technical services

14. Persistence
a. ... over long periods
b. ... in the face of difficulty

15. Promise
a. ... of initial idea
b. ... of later ideas

16. Prototyping
a. ... is a way to generate ideas
b. ... is a way to test ideas
c. ... is a way to elicit feedback
d. ... is a precursor to manufacture
e. ... is achieved through digital simulation

17. Representation
a. ... through sketching
b. ... through CAD use
c. ... through physical modelling

18. Requirements
a. , the discovering of new ones
b. , the resolution of conflicting ones
c. , the definition of them

19. Resistance
a. ... to one's own ideas

b. ... from other people 